\section{Home or community-based pulmonary rehabilitation for individuals with chronic obstructive pulmonary disease: a systematic review and meta-analysis}

\author{
Reabilitação pulmonar domiciliar ou comunitária \\ para indivíduos com doença pulmonar obstrutiva \\ crônica: revisão sistemática e meta-análise
}

\section{Rehabilitación pulmonar domiciliaria o comunitaria para individuos con enfermedad pulmonar obstructiva crónica: revisión sistemática y metaanálisis}




\section{Introduction}

Chronic obstructive pulmonary disease (COPD) is defined as a preventable and treatable disease state involving progressive airflow obstruction that is not fully reversible 1 . A chronic inflammatory process occurs that can produce changes in the bronchi (chronic bronchitis), bronchioles (obstructive bronchiolitis), and/or pulmonary parenchyma (pulmonary emphysema), leading to air flow limitation, caused primarily by smoking. The consequences can be systemic ${ }^{1,2}$. COPD is a leading cause of death worldwide - including Europe 3,4 , the United States 5, and Brazil 6. COPD was the sixth leading cause of death in the world in 1990 and fourth in 2000, and is estimated to reach third place by 2020 3. Estimated odds of death following hospitalization due to an exacerbation of COPD are $51 \% 7$.

Treatment of COPD can include smoking cessation, psychosocial monitoring, medication, and physical rehabilitation ${ }^{8}$. This set of interventions, involving a multidisciplinary team, is called pulmonary rehabilitation (PR). According to the American Thoracic Society (ATS) and European Respiratory Society (ERS), PR includes physical training as well as educational and behavioral changes intended to promote physical and psychological improvement in COPD 9.

COPD is a not fully reversible condition, since damage to pulmonary structures is permanent. Most studies on PR thus emphasize improvement of functional aspects and quality of life 10 . One of the main interventions studied in rehabilitation programs is thus physical exercise, with or without other program components. PR based on exercise involves aerobics, muscle-strengthening exercises, and in some cases strengthening of respiratory muscles ${ }^{11}$. Evidence suggests that exercise-based programs are the most effective in improving COPD symptoms, making exercise the main intervention to promote patients' independence and improve their quality of life 10,11.

The benefits of PR in treating COPD have been demonstrated in several studies that highlight an increase in functional capacity and endurance as well as a decrease in dyspnea perception 12. Despite limited evidence that PR is effective for increasing survival in COPD patients 10 , it can improve the feeling of dyspnea, quality of life, and exercise capacity and decrease the number of hospitalizations, all of which are predictors of mortality 12,13 .

PR is traditionally performed as outpatient pulmonary rehabilitation (OPR). According to national and international guidelines, it is costeffective and well documented in the literature 1,9,11,12. This study considered OPR as a PR mo- dality in a specialized outpatient setting. In a meta-analysis on the effects of OPR compared to a control group, even though the latter used important treatment modalities such as bronchodilators, pulmonary rehabilitation, which included physical rehabilitation, showed better results in quality of life and exercise capacity 14 . According to another systematic review, PR is effective when compared to control conditions for the same outcomes, even with different approaches in each physical exercise program ${ }^{15}$. A variety of physical training methods can be used during PR, including strength training, interval training, upper body training, inspiratory and expiratory muscle training, and transcutaneous electrical stimulation, in addition to aerobic training generally used in programs 9,16.

Some studies (including randomized clinical trials, RCTs) on the use of PR as home or community-based pulmonary rehabilitation (HCPR) rather than in an outpatient clinical setting (OPR) show positive results in improving exercise capacity and quality of life and a decreasing dyspnea sensation 17,18,19,20. We defined HCPR as a PR program developed in a non-specialized community health service, in a community center, or at the patient's home. Other RCTs that compared standard OPR to home or community-based PR show similar results and greater effectiveness of HCPR for some outcomes such as exercise capacity and sensation of dyspnea 20,21,22. Some systematic reviews 23,24,25 compare OPR to controls (no exercise), but none compare OPR and HCPR. Those systematic reviews showed that HCPR improved functional capacity and quality of life and reduced dyspnea sensation, but they used less comprehensive search strategies.

Although some studies have addressed PR in home and community settings, the benefits of this rehabilitation modality are still not clear for all the target outcomes. A wide variety of protocols are also used in rehabilitation programs, and the influence of these factors on the results requires more in-depth study. A better understanding of these aspects could inform health policies. The current study thus aimed to assess the effectiveness of HCPR compared to OPR or a control group for improving the commonly assessed outcomes (functional capacity, dyspnea perception, and quality of life) in patients with COPD, using a systematic literature review with meta-analysis.

\section{Method}

This systematic review and meta-analysis of RCTs followed the recommendations of the Cochrane Collaboration 26 and PRISMA Statement 27. 
Our primary outcomes were functional capacity and health-related quality of life, and our secondary outcome was self-report of dyspnea sensation. The study protocol was registered in the Centre for Reviews and Dissemination, University of York (PROSPERO) under number CRD42014007295 28,29. There were some modifications between the protocol and the final study due to the lack of data in the selected studies concerning some outcomes that we planned to analyze. We also planned to assess publication bias through tests of funnel plot asymmetry, comparing intervention effects estimated from individual studies against a measure of study size for each outcome. Nevertheless, this test is underpowered to distinguish chance from real asymmetry when the meta-analysis includes less than 10 studies 26 , which happened in all but one of the meta-analyses performed in the present review. Additionally, we needed to adopt different strategies for subgroup analyses, since few studies could be pooled for some of the selected outcomes.

\section{Eligibility criteria}

RCTs were selected for this review. Studies whose results did not include a control group (no exercise) or a comparison (OPR) or which did not use random drawing to refer patients to the groups were excluded. The review included studies whose participants were patients with COPD stages two or higher according to the Global Initiative for Chronic Obstructive Lung Disease (GOLD) 8 .

The selected studies involved HCPR - pulmonary rehabilitation at home or in a nonspecialized community center/health service compared to a control group and/or to a group that received OPR. The results needed to contain at least one of the following outcomes: performance in the Six-Minute Walk Test (6MWT), performance in the Incremental Shuttle Walk Test (ISWT), quality of life (Saint George's Respiratory Questionnaire - SGRQ or Chronic Respiratory Questionnaire - CRQ), or sensation of dyspnea (Medical Research Council - MRC). Outcomes were assessed at baseline, immediately upon conclusion of rehabilitation programs, and in follow-up evaluations when informed by the authors. Intervention was defined as a minimum period of four weeks.

\section{Search strategy}

Article searches were conducted from January 2014 to May 2015, independently of language or date of publication, in the following electronic databases: MEDLINE (PubMed), SCOPUS, Cochrane Central Register of Controlled Trials (CENTRAL), LILACS, Physiotherapy Evidence Database (PEDro), and Google Scholar. In addition, manual searches were made in the references of the studies found on this research topic. The search strategy included a combination of the following terms: "chronic obstructive pulmonary disease", "physical exercise", "physical rehabilitation", "home care services", and "community health services". These terms were associated with a highly sensitive search strategy for RCTs 26 . The complete search strategy used in PubMed, reproduced in the other databases with minor adjustments, can be accessed in the Supplementary material (https://www.dropbox.com/s/ w21i0iz37pv3kuc/Material\%20Suplementar\%20 13.03.2016.docx? $\mathrm{dl}=0$ ).

Searches for unpublished or in-progress studies were done in the clinical trials databases (WHO International Clinical Trials Registry Platform and ClinicalTrials.gov) as well as abstracts in the annals of important conferences in the area, such as the International Congress of Tuberculosis and Lung Disease (http://nritldcon gress.ir/en/), the International Symposium on Respiratory Disease - IRSD (http://www.isrd. org/), and COPD Conferences (http://www.cop dconferences.org).

\section{Selection of studies and data extraction}

In the first phase, the titles and abstracts of all studies identified during the searches were independently assessed by two reviewers (L.F.N. and M.H.R.) using the EndNote X3 software (Thomson Reuters. http://www.endnote.com). All abstracts and titles that did not contain sufficient information for assessment of inclusion and exclusion criteria were selected for evaluation of the full text.

In the second phase, two reviewers independently assessed the full texts and selected the studies according to predefined eligibility criteria. Disagreements between reviewers were resolved by consensus, and if necessary a third reviewer (T.R.G.) made the decision. Overall agreement among reviewers was excellent (kappa = 0.89 ).

Using a standard form, reviewers independently performed the data extraction on participants, interventions, and comparison of conditions and target outcomes, besides checking the selected studies' methodological quality. Disagreements were resolved by consensus or decided by the third reviewer. Whenever data were insufficient to assess the methodological quality or inclusion of the study in the meta-analysis, the 
original authors were contacted by e-mail for further information.

\section{Assessment of bias risk}

The methodological quality assessment considered the following characteristics of the selected studies: random sequence generation, blinding of researchers, blinding of outcome evaluators, selective data reporting, intention-to-treat analysis, and adequate description of losses and exclusions. Criteria for assessing each item in the studies' methodological quality followed the recommendations of the Cochrane Handbook of Systematic Reviews of Interventions 26 , and the tables with the contents of the bias risk assessment were made in the Review Manager 5.1 software (Cochrane's Informatics \& Knowledge Management Department; http://tech.cochrane. org/revman).

\section{Data analysis}

The meta-analysis was performed using calculation of the mean difference with random effects model, 95\% confidence intervals (95\%CI), and effect measures obtained through the postintervention values. The studies were analyzed separately, according to type of intervention vs. comparison: HCPR vs. control group, or HCPR vs. OPR. The target outcomes were performance in 6MWT, performance in ISWT, quality of life (SGRQ or CRQ), and sensation of dyspnea (MRC).

All the analyses used Review Manager 5.1, and the random effects model was used to account for any potential heterogeneity following different interventions in diverse study settings. Statistical heterogeneity of treatment effect between studies was assessed using Cochran's $\mathrm{Q}$ test and the inconsistency test $\left(\mathrm{I}^{2}\right)$, in which values below $40 \%$ do not pose a problem, values between $30 \%$ and $60 \%$ mean moderate heterogeneity, values between $50 \%$ and $90 \%$ mean substantial heterogeneity, and values between $75 \%$ and $100 \%$ mean considerable heterogeneity 23 . Heterogeneity, when found, was evaluated by the researchers, and the possible causes were explored through subgroup analyses. Finally, assessment of the quality of evidence generated by this systematic review was summarized for each outcome and type of comparison using the GRADE Profiler software (Cochrane's Informatics \& Knowledge Management Department; http:// tech.cochrane.org/gradepro).

\section{Results}

\section{Description of studies}

The initial search identified 3,172 studies, excluding duplicates. Of these, 58 were considered potentially relevant and 23 studies 17,18,19,30,31,32,33, $34,35,36,37,38,39,40,41,42,43,44,45,46,47,48,49,50$ met the eligibility criteria and were included in this review. One of the selected studies appeared in two distinct publications 49,50 in which the same intervention was applied to the same patients but describing different outcomes. Figure 1 shows the flow diagram for the study search and selection.

The 23 selected studies involved a total of 1,258 individuals of both sexes. Thirteen studies were done in Europe 17,19,21,31,33,38,42,43,45,46, 48,49,50, six in Asia 30,36,39,40,44,47, two in Australasia 34,35 , one in North America 41, and one in South America 32. Among the studies included in the review, $1917,18,19,30,31,32,33,34,36,38,39,40,42,43$, $44,46,47,48,49,50$ compared HCPR to control group ( $\mathrm{n}=$ total 893; n HCPR = 485), while four 35,37,41,45 compared HCPR to OPR ( $\mathrm{n}$ total = 375; n HCPR = 178). No studies reported harmful effects related to HCPR during interventions.

As for HCPR, all studies used at least one aerobic component $(43.5 \%$ walking, $17.4 \%$ biking, $8.7 \%$ climbing stairs, and $30.4 \%$ a combination of these exercises), and most included strength training for upper and lower limbs and respiratory muscles, as well as educational measures. Some studies used different ways to encourage patients to exercise, such as walking to the beat of music or exercises accompanying demo videos, but most simply advised patients to walk with or without a pedometer and to fill in exercise diaries. Table 1 shows the characteristics of studies, patients, and interventions.

\section{Risk of bias}

Evidence of selective reporting was not been found in any of the selected studies, and $86.96 \%$ properly described tracking losses and exclusions. More than half (56.52\%) presented low risk of bias in the randomization sequence generation, $30.44 \%$ had low risk of bias in the blinding of outcome reviewers, and $26.08 \%$ in the blinding of personnel. It was not possible to clearly assess the risk of bias in the random sequence generation in $39.13 \%$, blinding of the outcome reviewers in $26.08 \%$, or blinding of teams in $21.73 \%$ of the studies. More than one-third of the studies $(39.13 \%)$ conducted intention-to-treat analyses. The studies' methodological quality was generally moderate (Figures 2 and 3). Considering assessment of publication bias in the systematic review, 


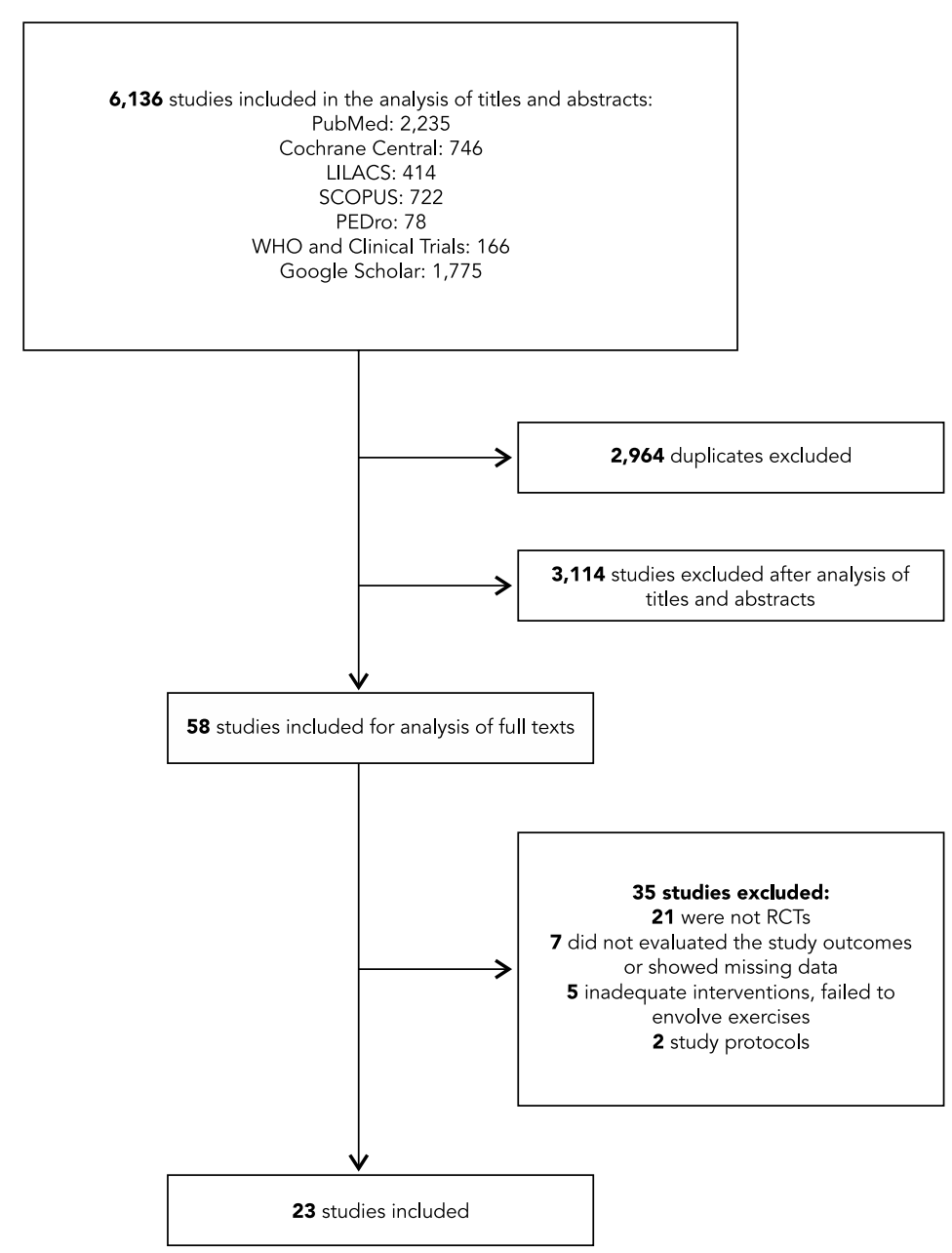

RCTs: randomized clinical trials.

a test of funnel plot in the quality of life outcome (assessed by the CRQ) comparing HCPR to controls (the only meta-analysis that included more than 10 studies, ensuring the minimum power to conduct the test), showed little evidence of asymmetry. (Supplementary material: https://www. dropbox.com/s/w21i0iz37pv3kuc/Material\%20 Suplementar\%2013.03.2016.docx?dl=0).

\section{Effects of interventions}

\section{- Analysis 1: HCPR vs. control group}

(a) Functional Capacity and Dyspnea: Ten studies $30,31,33,36,40,44,46,47,48,50(n=461)$ assessed functional capacity with the 6MWT and seven used the ISWT $18,32,34,38,39,42,43$ ( $\mathrm{n}=321$ ). Four studies 19,38,43,48 ( $\mathrm{n}=280$ ) evaluated dyspnea using the MRC. The meta-analysis indicated significant improvement in the 6MWT (33.79 meters, 95\%CI: 6.03 to $61.54, \mathrm{I}^{2}=76 \%$ ), but due to the high heterogeneity, a subgroup analysis was done on studies including patients with $\mathrm{FEV}_{1}$ above and below $50 \%$ of predicted. Subgroup analysis 
Table 1

Characteristics of studies, patients, and interventions included in the systematic review.

\begin{tabular}{lcc}
\hline $\begin{array}{l}\text { Study/Country/ } \\
\text { Outcome }\end{array}$ & $\begin{array}{c}\text { Comparison/Time } \\
\text { intervention }\end{array}$ & Population \\
\hline
\end{tabular}

Akinci \& Olgun 30/

Turkey/6MWT, SRGQ

Home PR vs.
controls/3 months

COPD patients with GOLD stages III and IV

Intervention ( $\mathbf{n}=16)$ : Age: $71.8 \pm 7.8$ years; $\mathrm{FEV}_{1}(\%$ predicted): $36.1 \pm 10.8$

Controls $(n=16)$ : Age:

$65.1 \pm 10.2$ years; $F V_{1}(\%$ predicted): $39.2 \pm 11.0$

Selection: Patients from an output clinic at the University Hospital in Istanbul

Home PR vs.

Behnke et al. 17/

Germany/CRQ controls/6 months

Cambach et al. 31/

Community PR vs. Netherlands/6MWT, CRQ

Dias et al. 32/Brazil/ ISWT controls/3 months

Home PR vs. controls/6 months
COPD patients with GOLD stages III and IV

Intervention ( $n=15)$ : Age: $64.0 \pm 1.9$ years; $F E V_{1}$ (\% predicted): $34.1 \pm 7.4$

Controls ( $n=15)$ : Age: 68.0 \pm 2.2 years; $F V_{1}(\%$ predicted): $37.5 \pm 7.5$ Selection: Patients in hospital after an exacerbation

COPD patients with GOLD stages II and III

Intervention ( $\mathrm{n}=15)$ :

Age: $62 \pm 5$ years; $\mathrm{FEV}_{1}(\%$ predicted): $59 \pm 16$

Controls ( $n=8)$ : Age: $62 \pm 9$ years; $F \mathrm{VV}_{1}$ (\% predicted): $60 \pm 23$

Selection: Recruited by general practitioner or pulmonary physician COPD patients with GOLD stages II and III

Intervention ( $n=12)$ : Age: $66.5 \pm 5.8$ years; $\mathrm{FEV}_{1}(\%$ predicted): $55.14 \pm 24.8$

Controls ( $n=11)$ : Age: $64.0 \pm 5.8$ years; $\mathrm{FEV}_{1}(\%$ predicted): $60.0 \pm 20.1$

Selection: Patients that underwent outpatient care, stable, without exacerbation in the previous 30 days
Home PR: Unsupervised and at-home breathing (labial frenum and diaphragmatic breathing) as well as aerobic exercises for lower limbs (30-minute walk) and upper limbs (arm exercises -15 repetitions of each exercise in 1 minute). Upper limb exercises simulated activities such as stirring soup in a pot, pulling an anchor up, hitting a punching bag, paddling, waxing the car, laps of crawl and breaststroke swimming, chopping firewood, doing air scissors movements with the arms, and playing drums. Exercises were taught in the first session, and in two other sessions, adjustments and corrections were made as problems were observed in the reports patients completed afterwards. The exercises did not need to be done all at once, and there was a follow-up every 15 days in the first month and once a month in the second and third months.

Controls: Participants did not receive any orientation from the healthcare team on the exercises and followed a standard treatment plan Home PR: 10 days training walking in hospital, plus 30 minutes/day of breathing exercises and medication. Afterwards patients participated in a supervised program for six months of walking integrated into daily activities like going to the mall. Walks were 3 times a day, to $125 \%$ of the greatest distance traveled by each individual in the 6MWT. Patients recorded the distance traveled and the time spent on each walk. In the first three months, patients were visited every two weeks to assess their health status, after which supervision was monthly, by telephone.

Controls: Same 10-day treatment as home-based PR, plus standard medication, 30 minutes of breathing exercises a day during hospitalization. After discharge, patients were advised to exercise, but without specific

\section{guidelines}

Community PR: Breathing techniques and bronchial hygiene, upper and lower limb exercises, educational guidance, relaxation techniques (once a week for 45 minutes), and recreational activities. Sessions were supervised by physical therapists with groups of 3 to 4 patients, 3 times a week, lasting 90 minutes. Exercises were twice a week using a cycle Ergometer (60 to $75 \%$ of Wmax - time increasing from 3 to $12 \mathrm{~min}$ ), rowing machine, or climbing stairs (60\% of maximum heart rate - increasing from 3 to 5 minutes). Recreational activities were swimming, skating, and bicycling for 45 minutes once a week to reach $\geq 60 \%$ of maximum heart rate for $\geq 30$ minutes.

Controls: Only standard medication

Home PR: Patients received a booklet on COPD and quality of life and a series of exercises, including stretching, respiratory reeducation, and aerobic exercises for upper limbs (with individual load at $50 \%$ of assessment load). Patients were instructed to walk for 40 minutes three times a week at $85 \%$ peak oxygen consumption. Patients were encouraged to walk on treadmill on the first day to adapt to the speed they would walk at home. Patients were instructed by individual tutors to minimize errors in performing exercises and to correctly complete an exercise diary. Two weekly visits were carried out individually to monitor exercises (85\% of maximum heart rate in the incremental test).

Controls: Participants received a booklet on COPD and quality of life, and a series of exercises, including stretching and respiratory reeducation exercises three times a week, in addition to visits to the outpatient center twice a week to review their exercise routine

(continues) 
Table 1 (continued)

\begin{tabular}{lccc}
\hline $\begin{array}{l}\text { Study/Country/ } \\
\text { Outcome }\end{array}$ & $\begin{array}{c}\text { Comparison/Time } \\
\text { intervention }\end{array}$ & Population & Interventions and controls/comparison conditions
\end{tabular}

Du Moulin et al. $33 / \quad$ Home PR vs.
Germany/6MWT,
CRQ

Effing et al. 34/ Netherlands/ISWT, CRO

Elliott et al. 35/ Australia/6MWT, CRO

Ghanem et al. 36/ Egypt/6MWT, CRQ

Community PR vs. controls/12 months

Community PR vs. OPR/3 months

Home PR vs. controls/2 months
COPD patients with GOLD stages II and III

Intervention ( $\mathbf{n}=10)$ : Age: $67 \pm 2.4$ years; $\mathrm{FEV}_{1}$ (\% predicted): $58.6 \pm 3$

Controls $(n=10)$ : Age: $72 \pm 2.3$ years; $F V_{1}(\%$ predicted): $58.4 \pm 4$

Selection: Patients from an output center in Hamburg

COPD patients with GOLD stages II and IV Intervention ( $\mathbf{n}=71$ ): Age: $62.5 \pm 2.1$ years; $F V_{1}$ (\% predicted): $42.7 \pm 5.9$

Controls ( $n=68)$ : Age:

$68.7 \pm 2.1$ years; $F E V_{1}(\%$ predicted): $46.3 \pm 4.4$

Selection: Patients from an output clinic at Medisch Spectrum Hospital, Netherlands

COPD patients with GOLD stages II and IV

Intervention ( $\mathbf{n}=9)$ ): Age: $62.5 \pm 2.1$ years; $\mathrm{FEV}_{1}$ (\% predicted): $49.6 \pm 14.2$ Controls ( $n=22)$ : Age: predicted): $50.7 \pm 17.0$ Selection: Inpatients and outpatients of the Respiratory Medicine Department, Royal Perth Hospital and Sir Charles Gairdner Hospital, with normal breathless

COPD patients with GOLD stages II to IV
Patients received 3 weeks of outpatient PR, consisting of 20 hours of exercise, 11 hours of education, 5 hours of nutritional orientation, 10 hours of respiratory therapy, 5 hours of relaxation, 3 hours of psychological support, and 5 hours of support for smoking cessation. Exercises were done on treadmill, cycle ergometer, and strength exercises for lower/upper limbs and trunk.

Home PR: Walk $125 \%$ of distance traveled in 6MWT by the end of outpatient PR, in no more than 15 minutes, 3 times a day. Alternatively, patients could combine the three workouts in a single daily workout. Patients completed a training diary to be sent to the researchers every 4 weeks, when they received new diaries. Motivational phone calls were made every 4 weeks.

Controls: Patients were encouraged to maintain their normal activities of daily living, but received no orientation on their physical activities

Both groups received self-monitoring COPD guides and attended small group sessions with information and guidelines for smoking cessation, monitoring of symptoms, and breathing exercises.

Community PR: Patients received guidance on bicycling, walks, climbing stairs, and weight exercises for upper and lower limbs. Patients received a diary with illustrations of exercises and where they should record their activities, feelings, and fatigue levels. A physical therapist made weekly visits to adjust the exercises according to the diaries.

Controls: Patients received self-monitoring guides and usual medication $68.7 \pm 2.1$ years; $\mathrm{FEV}_{1}$ (\% Intervention ( $n=25)$ : Age: $59.96 \pm 11.59$ years; $\mathrm{FEV}_{1}$ (\% predicted): $36.24 \pm 14.17$

Controls $(n=14)$ : Age: $56.43 \pm 9.03$ years; $\mathrm{FEV}_{1}$ (\% predicted): $29.0 \pm 10.91$

Selection: Patients admitted to the Chest Department in a tertiary hospital
Community PR: Patients participated in community group exercises. The program varied according to the distance from the patient's home, schedule, length of sessions, and physical performance. Depending on ability, patients had sessions of general exercises: running for over 60-yearolds or individual sessions conducted by professionals. Sessions lasted 1.5 hours twice a week and involved warmup and stretching, walks, general exercises, or circuits for lower limb strengthening with weights, cool-down, and stretching. Exercises focused on functional mobility and did not change

$$
\text { over time. }
$$

Outpatient PR: Conducted in an outpatient center, twice a week with sessions of 1.5 hours. The program included warmup and stretching,

muscle strengthening circuit of 30 minutes (upper/lower limbs and

abdominal exercises), 30 minutes of aerobic training (treadmill, walking in the hospital hallway, and cycle ergometer), cool-down, and stretching Sessions were done in groups of 10 to 12 patients and exercises were prescribed according to each patient's initial assessment, in addition to ongoing review by physical therapists

Before discharge all patients attended talks on lifestyle, anatomy and physiology, disease pathology, pulmonary medication, oxygen therapy, avoiding environmental irritants, and prevention and management of respiratory infections. They were interviewed and received a booklet on exercising as a reminder for home.

Home PR: In addition to standard medication, they were also instructed to exercise, including resistance training (walking or cycling) and strengthening of upper and lower limbs (6 to 10 repetitions - interval training and rest according to individual tolerance) for two months. After the series of exercises, patients had to stretch ischiotibial muscles, quadriceps, shoulders, neck, and lumbar spine.

Controls: Patients received standard medication following discharge 
Table 1 (continued)

\begin{tabular}{lcc}
\hline $\begin{array}{l}\text { Study/Country/ } \\
\text { Outcome }\end{array}$ & $\begin{array}{c}\text { Comparison/Time } \\
\text { intervention }\end{array}$ & Population
\end{tabular}

Güell et al. 37/ Spain/6MWT, CRQ

Hernández et al. 38/ Spain/ISWT, CRQ, $\mathrm{MRC}$

Ho et al. 39/Taiwan/ ISWT, SRGQ

Jang et al. 40/South Korea/6MWT
Home PR vs. OPR/9 weeks of intervention plus 6 months followup

Home PR vs. controls/3 months

Home PR vs. controls/4 months

Home PR vs. controls/2 months
COPD patients with GOLD
stages III and IV Intervention ( $\mathrm{n}=23$ ): Age: $66.0 \pm 5.8$ years; $\mathrm{FEV}_{1}$ (\% predicted): $39.0 \pm 7.6$

Controls $(n=28)$ : Age: $63.2 \pm 6.6$ years; $\mathrm{FEV}_{1}$ (\% predicted): $37.5 \pm 7.1$

Selection: Patients referred for pulmonary rehabilitation at a Spanish hospital

COPD patients with GOLD stages II to IV

Intervention ( $\mathbf{n}=\mathbf{2 0})$ : Age: $64.3 \pm 8.3$ years; $\mathrm{FEV}_{1}$ (\% predicted): $41.7 \pm 15.6$

Controls ( $n=17)$ : Age:

$63.1 \pm 6.9$ years; $\mathrm{FEV}_{1}$ (\% predicted): $40.0 \pm 16.4$

Selection: Stable patients with optimal drug management

COPD patients with GOLD stages II to IV

Intervention ( $\mathrm{n}=\mathbf{2 0}$ ): Age:

$73.1 \pm 11.2$ years; FEV 1 (\% predicted): $60.6 \pm 18.9$

Controls $(n=21)$ : Age:

$75.1 \pm 9.6$ years; $\mathrm{FEV}_{1}$ (\% predicted): $61.2 \pm 26.3$

Selection: Stable patients, without use of $\mathrm{O}_{2}$ or

exacerbations in previous month

COPD patients with GOLD stages II to IV

Intervention ( $\mathrm{n}=18)$ : Age: $64.5 \pm 2.6$ years; $\mathrm{FEV}_{1}$ (\% predicted): $45.31 \pm 11.07$

Controls ( $n=18)$ : Age: $65.7 \pm 2.2$ years; $F E V_{1}$ (\% predicted): $39.2 \pm 11.0$

Selection: Patients without exacerbations from the physiotherapy department of the Yeungnam University
All patients received standard medical treatment and attended two educational sessions on the disease for 2 weeks, and were instructed on how to drain secretion and perform breathing exercises.

Home PR: Breathing exercises three times a week, with two sets of 15 minutes with threshold. The load for inspiratory exercises amounted to $40 \%$ of maximum inspiratory pressure. They performed strength training for upper limbs and daily walks on the street, unsupervised, at $4 \mathrm{~km} /$ hour controlled by a pedometer. The first week included a 15-minute walk, from the second to fourth week a 30-minute walk, and 45 minutes from the fifth to the ninth week. Patients were instructed to walk up and down stairs for 5 minutes before and after walks.

Outpatient PR: Patients performed the same breathing exercises, plus upper limb strength training consisting of 30 minutes of weightlifting (starting at $0.5 \mathrm{~kg}$ on each arm, increasing to $1 \mathrm{~kg}$ each week until patient's maximum tolerance). Training of lower limbs was a 30-minute exercise on a cycle ergometer

Home PR: Walking at home or on flat ground near their homes for at least 20 meters. Marks were made at 0, 10, and 20 meters so that patients could identify the points. They received a cassette with audible signals so that they matched the speed of the walk to the demarcated points. Intensity of training was individualized at a constant speed two levels below the maximum obtained in the shuttle test. Trainings were held six days a week, lasting an hour, for 12 weeks. Every two weeks, patients went to hospital to assess clinical status and treatment adherence.

Controls: Patients received standard medication plus visits to hospital every two weeks for clinical assessment and treatment supervision

\section{Home PR: Patients received instructions on warmup and cool-down} exercises, and training consisted of walking to the rhythm of a song. Initial training was $80 \% \mathrm{VO}_{2}$ max and increased gradually, based on distance of shuttle test, done monthly. Intensity of training increased with speed of the music. Patients chose their favorite music, and the beat was adjusted to timing of their steps to travel a certain distance. Training lasted 30 minutes, five times a week for 16 weeks. Patients also received a booklet on COPD self-care, benefits of exercises, and precautions when exercising. They were encouraged to complete an exercise diary.

Controls: Patients also received the booklet on COPD self-care, benefits of exercises, and precautions when exercising. They were also encouraged to exercise five times a week and keep an exercise diary

Home PR: Patients received educational guidance about COPD, medication management and smoking cessation, and watched videos showing interviews of experiences of other people who underwent PR. They performed respiratory training, with exercises for inspiratory and expiratory muscles. Physical training was done with elastic bands to strengthen chest, shoulders, and upper limbs. In the walks they used pedometers to keep heart rate frequency between $40 \%$ and $60 \%$. They were instructed to perform relaxations and received counseling. The trainings were conducted five times a week. Patients were given diaries to record their trainings, besides receiving weekly calls to encourage them to remain in the program.

Controls: Patients received the same educational measures, but did not do the exercises

(continues) 
Table 1 (continued)

\begin{tabular}{lcc}
\hline $\begin{array}{l}\text { Study/Country/ } \\
\text { Outcome }\end{array}$ & $\begin{array}{c}\text { Comparison/Time } \\
\text { intervention }\end{array}$ & Population
\end{tabular}

Maltais et al. 41/

Canada/6MWT, SRGQ, CRQ

Man et al. 18/England/ ISWT, SGRQ, CRQ

Moore et al. 42/United Kingdom/ISWT, CRO
Home PR vs. OPR/3 months of intervention plus 12 months follow-up

Community PR vs. controls/3 months

Community PR vs. controls/6 weeks
COPD patients with GOLD stages II to IV

Intervention ( $n=126$ ):

Age: $66 \pm 9$ years; FEV $1 \%$ predicted): $43.0 \pm 13.0$

Controls $(n=126)$ : Age: $66 \pm 9$ years; $F V_{1}(\%$ predicted): $46.0 \pm 13.0$

Selection: Patients from specialized pulmonary centers, stable
Prior to randomization, patients attended a four-week program on education for self-care.

Home PR: For eight weeks, three times a week, patients were instructed to perform self-monitored aerobic exercises and muscle strengthening.

Patients received staff visits to verify their understanding of the exercises. Exercising used portable cycle ergometers on loan to patients during training. Intensity target was $60 \%$ of the peak reached during the incremental test, to be maintained for 40 minutes. Patients were instructed to decrease the intensity of training in case of intense dyspnea. They performed stretch exercises and received supplemental oxygen if necessary, as with outpatients. Training diaries were completed, and during the intervention patients received weekly calls to reinforce the importance of exercises and to detect problems.

Outpatient PR: Patients attended three sessions per week for eight weeks of workouts on stationary bicycles for 25 to 30 minutes per session, to maintain $80 \%$ of the peak reached in the incremental test. In case they presented desaturation $\left(\mathrm{SpO}_{2}<88 \%\right)$ or already used oxygen at home,

patients received supplemental oxygen. The researchers decreased the exercise intensity in case of severe dyspnea or very high heart rate. Strength exercises lasted 30 minutes, ranging from one to three sets of 10 repetitions. When the goal was reached, resistance was increased with elastic bands, weights, or gym anklets.

Patients in both groups were encouraged to maintain their workout routine with their own equipment without supervision for a period of 12 months.

Every two months, patients were contacted to verify their adherence to the program

COPD patients with GOLD stages II to IV

Intervention ( $\mathbf{n}=18)$ : Age: $70.7 \pm 9.3$ years; $\mathrm{FEV}_{1}(\%$ predicted): $41.7 \pm 18.9$

Controls $(n=16)$ : Age: 69.6 \pm 9.2 years; $\mathrm{FEV}_{1}$ (\% predicted): $36.7 \pm 14.9$

Selection: Patients admitted to King's College Hospital in London with primary diagnosis of acute exacerbation of COPD

COPD patients with GOLD stages II to IV

Intervention ( $\mathbf{n}=10)$ : Age: $70.0 \pm 13.0$ years; $\mathrm{FEV}_{1}$ (\% predicted): $40.0 \pm 10.8$

Controls ( $n=10)$ : Age:

$70.5 \pm 16.13$ years; $\mathrm{FEV}_{1}$ (\% predicted): $41.5 \pm 20.17$

Selection: Patients from a PR waiting list
All patients were discharged 10 days after COPD exacerbation. Community PR: Patients received individual exercise programs in one of three centers in two districts of London and were encouraged to exercise for three months, $\geq 20$ minutes a day. Sessions lasted two hours and consisted of one hour of exercise (walking and cycling, upper and lower limb strengthening) and one hour of educational activities aimed at selfcare, nutrition, and healthy habits. Controls: Usual medication was maintained

Community PR: Patients watched two videos. The first (19 minutes) featured information on benefits of exercise in COPD treatment and a COPD patient's testimony on his experience and benefits of exercises. The second (30 minutes) taught patients how to perform a series of exercises four times a week for six weeks. Patients received professional guidance on how to perform the exercises and were advised to stop if they feel pain or any other discomfort and to seek the physical therapist or physician in an emergency. Exercises included warmup, strength and high intensity aerobic workouts for upper and lower limbs, stretching, and cool down.

Controls: Patients received an educational booklet and standard medication

(continues) 
Table 1 (continued)

\begin{tabular}{|c|c|c|c|}
\hline $\begin{array}{l}\text { Study/Country/ } \\
\text { Outcome }\end{array}$ & $\begin{array}{c}\text { Comparison/Time } \\
\text { intervention }\end{array}$ & Population & Interventions and controls/comparison conditions \\
\hline $\begin{array}{l}\text { Murphy et al. 43/ } \\
\text { Ireland/ISWT, MRC }\end{array}$ & $\begin{array}{l}\text { Home PR vs. } \\
\text { controls/6 weeks }\end{array}$ & $\begin{array}{l}\text { COPD patients with GOLD } \\
\text { stages III and IV } \\
\text { Intervention ( } \mathrm{n}=16) \text { : } \\
\text { Age: } 67 \pm 9.7 \text { years; } \mathrm{FEV}_{1}(\% \\
\text { predicted): } 38.0 \pm 12.0 \\
\text { Controls }(\mathrm{n}=15): \text { Age: } \\
65 \pm 11 \text { years; FEV } 1 \% \\
\text { predicted): } 42.0 \pm 12.0 \\
\text { Selection: } 31 \text { consecutive } \\
\text { patients referred by hospital } \\
\text { treatment program to COPD } \\
\text { home follow-up }\end{array}$ & $\begin{array}{l}\text { Community PR: Home sessions supervised by physical therapist twice a } \\
\text { week for six consecutive weeks, totaling } 12 \text { sessions. Sessions lasted } 30 \text { to } \\
40 \text { minutes. On the other days, patients exercised for } 15 \text { minutes, keeping a } \\
\text { diary. Aerobic exercises were walking up and down stairs, sitting down and } \\
\text { getting up from a chair; elastic bands were used for strengthening upper } \\
\text { limbs. Patients were supposed to exercise maintaining dyspnea level from } 3 \\
\text { to } 5 \text { on the Borg scale. } \\
\text { Controls: Patients received medication without any change in lifestyle or } \\
\text { physical activity }\end{array}$ \\
\hline $\begin{array}{l}\text { Oh 44/South } \\
\text { Korea/6MWT, CRQ }\end{array}$ & $\begin{array}{l}\text { Home PR vs. } \\
\text { controls/2 months }\end{array}$ & $\begin{array}{l}\text { COPD patients with GOLD } \\
\text { stages II to IV } \\
\text { Intervention ( } \mathrm{n}=15) \text { : Age: } \\
64.8 \pm 7.84 \text { years; } \mathrm{FEV}_{1}(\% \\
\text { predicted): } 42.12 \pm 15.07 \\
\text { Controls }(\mathrm{n}=8) \text { : Age: } \\
66.8 \pm 12.29 \text { years; } \mathrm{FEV}_{1}(\% \\
\text { predicted): } 44.91 \pm 17.75 \\
\text { Selection: Subjects were } \\
\text { recruited from an outpatient } \\
\text { respiratory clinic at a large } \\
\text { university hospital in Korea }\end{array}$ & $\begin{array}{l}\text { Home PR: Patients received guidelines and a booklet on medication, } \\
\text { energy-sparing techniques, bronchial hygiene, and nutrition. They } \\
\text { performed inspiratory muscle training five times a day, five minutes each } \\
\text { session, with the PFLEX equipment (Healthscan, USA) and increased the } \\
\text { load whenever possible at their sole discretion. For physical training, } \\
\text { different exercises like walking and climbing stairs (five times a day - } 10 \\
\text { reps each time) were used. Muscle strengthening of upper and lower limbs } \\
\text { was done with elastic tubes. They also had Jacobson's relaxation technique } \\
\text { sessions twice a day, when waking up and before sleeping, and received } \\
\text { phone calls twice a week. } \\
\text { Controls: Patients only received educational guidelines at the beginning of } \\
\text { the study }\end{array}$ \\
\hline $\begin{array}{l}\text { Puente-Maestu } \\
\text { et al. } 45 / \text { Spain/CRQ }\end{array}$ & $\begin{array}{c}\text { Home PR vs. OPR/2 } \\
\text { months }\end{array}$ & $\begin{array}{l}\text { COPD patients with GOLD } \\
\text { stages III and IV } \\
\text { Intervention ( } \mathbf{n}=20) \text { : Age: } \\
65.5 \pm 4.7 \text { years; FEV }{ }_{1}(\% \\
\text { predicted): } 40.0 \pm 6.0 \\
\text { Controls }(\mathbf{n}=21): \text { Age: } \\
63.3 \pm 4.3 \text { years; FEV }(\% \\
\text { predicted): } 41.0 \pm 6.0 \\
\text { Selection: Patients were } \\
\text { referred to the authors by } \\
\text { their pulmonologists }\end{array}$ & $\begin{array}{l}\text { Home PR: Patients received a pedometer and were instructed to walk } 3 \text { to } \\
4 \mathrm{~km} \text { on flat terrain, for one hour, four times a week, maintaining moderate } \\
\text { dyspnea for at least } 10 \text { minutes in each workout. The pedometer was } \\
\text { adjusted to the length of their step, and patients completed a diary with } \\
\text { the number of steps per day. Patients attended the outpatient center once } \\
\text { a week to have their data assessed, and were encouraged to continue. } \\
\text { There was no direct supervision of the walks. } \\
\text { Outpatient PR: Patients in this group walked on a treadmill, supervised by } \\
\text { a physical therapist, at } 3 \mathrm{~km} / \mathrm{h} \text {, with a target of } 70 \% \mathrm{VO}_{2} \text { max and increasing } \\
\text { the treadmill distance } 2 \% \text { each week if they tolerated it. Individuals trained } \\
\text { four times a week, } 60 \text { minutes a day, and could divide the session into three } \\
\text { parts with } 10 \text {-minute intervals }\end{array}$ \\
\hline $\begin{array}{l}\text { Resqueti et al. 19/ } \\
\text { Spain/CRQ, MRC }\end{array}$ & $\begin{array}{l}\text { Home PR vs. } \\
\text { controls/9 weeks of } \\
\text { intervention plus } 6 \\
\text { months follow-up }\end{array}$ & $\begin{array}{l}\text { COPD patients with GOLD } \\
\text { stages III and IV } \\
\text { Intervention ( } \mathbf{n}=19): \text { Age: } \\
66.9 \pm 5.8 \text { years; } \mathrm{FEV}_{1}(\% \\
\text { predicted): } 27.5 \pm 9.0 \\
\text { Controls }(\mathbf{n}=19): \text { Age: } \\
68.5 \pm 7.0 \text { years; } F E V_{1}(\% \\
\text { predicted): } 29.6 \pm 8.0 \\
\text { Selection: Patients } \\
\text { attending an outpatient } \\
\text { clinic at two Spanish } \\
\text { Universities }\end{array}$ & $\begin{array}{l}\text { Both groups participated in a nine-week program with an hour educational } \\
\text { sessions and conventional physical therapy (30 minutes) for bronchial } \\
\text { hygiene, diaphragmatic breathing, and labial frenum. } \\
\text { Home PR: Patients began in the second week of intervention with three } \\
\text { sessions in the hospital. Each session included exercises on a stationary } \\
\text { bike for five minutes at maximum working capacity of } 30 \text { watts, } 2 \text { minutes } \\
\text { rest, and climbing stairs for 5-15 minutes, depending on patient's tolerance. } \\
\text { Upper limb strengthening used 15-30-minute sessions, initially without } \\
\text { weights, increasing gradually according to tolerance. Inspiratory muscle } \\
\text { training for } 15 \text { minutes with fixed load of } 30 \% \text { maximum inspiratory force. } \\
\text { From second to ninth week, patients followed the program at home, five } \\
\text { times a week for } 1.30 \text { hours, performing the exercises they had learned. } \\
\text { Controls: Patients were encouraged to continue respiratory physical therapy } \\
\text { exercises and walking at home, unsupervised. They were asked to record } \\
\text { their daily activities on a specific form }\end{array}$ \\
\hline
\end{tabular}

(continues) 
Table 1 (continued)

\begin{tabular}{|c|c|c|}
\hline $\begin{array}{l}\text { Study/Country/ } \\
\text { Outcome }\end{array}$ & $\begin{array}{c}\text { Comparison/Time } \\
\text { intervention }\end{array}$ & Population \\
\hline $\begin{array}{l}\text { Román et al. 46/ } \\
\text { Spain/6MWT, CRQ }\end{array}$ & $\begin{array}{c}\text { Home PR vs. } \\
\text { controls/9 months }\end{array}$ & $\begin{array}{l}\text { COPD patients with GOLD } \\
\text { stages II to IV } \\
\text { Intervention ( } n=20 \text { ): Age: } \\
64.9 \pm 6.39 \text { years; FEV }(\% \\
\text { predicted): } 60.9 \pm 10.5 \\
\text { Controls ( } n=15 \text { ): Age: } \\
64.1 \pm 8.2 \text { years; FEV } 1 \%\end{array}$ \\
\hline
\end{tabular}

Selection: Patients referred by family physicians from seven centers in Spain

Singh et al. 47/ India/6MWT, CRO

van Wetering et al. ${ }^{48 /}$ Netherlands/SRQ, MRC
Home PR vs. controls/1 month

Home PR vs. controls/4 months
COPD patients with GOLD stages III and IV

Intervention ( $\mathbf{n}=\mathbf{2 0})$ : Age: $59.37 \pm 6.4$ years; FEV $_{1}(\%$ predicted): $28 \pm 7.5$

Controls ( $n=20$ ): Age: $59.3 \pm 6.5$ years

$\mathrm{FEV}_{1}$ (\% predicted): $26 \pm 7.1$

Selection: Stable COPD patients

COPD patients with GOLD stages II to IV

Intervention ( $\mathbf{n}=\mathbf{8 7})$ : Age:

$65.9 \pm 8.8$ years; $\mathrm{FEV}_{1}(\%$ predicted): $58 \pm 17$

Controls ( $n=87$ ): Age:

$67.2 \pm 8.9$ years; $F_{1} V_{1}(\%$ predicted): $60 \pm 15$

Selection: Patients under supervision by the department of respiratory medicine at two general hospitals in Netherlands
Interventions and controls/comparison conditions

Prior to randomization patients were divided into three groups. Two received $P R$ in primary care centers and one received no intervention (controls). After the initial period, the groups that performed PR in primary care centers were divided into one group that received maintenance at home and the other that did not receive any further intervention. We compared the groups with PR in the primary care centers for three months and that were then divided into home PR or no further intervention (control2), in order to have the same baseline parameters. The two groups underwent three months of community PR in primary health care centers involving three weekly sessions, 60 minutes each. Educational sessions, respiratory physical therapy (15 minutes, including breathing and diaphragm control and exercises for the chest and abdomen) and low- intensity exercises for peripheral muscles (45 minutes of abdominal exercises with load for lower and upper limbs -8 to 10 repetitions for each exercise).

Home PR: Patients continued receiving professional visits once a week, for nine months, in order to keep the exercises learned in the outpatient program.

Control2: Patients received routine care accompanied by a doctor and a nurse

Home PR: Patients were instructed to do breathing exercises (labial frenum and diaphragmatic breathing), removal of secretions (controlled cough and postural bronchial drainage), lower limb exercises (walking on a flat surface twice a day at submaximal speed while retaining labial frenum), and energysparing techniques. Exercises lasted 30 minutes, to be done twice daily. Patients received weekly visits to monitor their exercising. Controls: Patients maintained usual medication

Home PR: For four months, patients visited physical therapist of their locality twice a week, who instructed them to do aerobic exercises (walks or cycle Ergometer) and four exercises for upper and lower limbs. The visits lasted 30 minutes and patients were instructed to perform the exercises twice a day at their homes without the need of any special equipment. They received nutritional guidance from a nutritionist, counseling to stop smoking and a book with educational information about the disease.

Controls: Patients received only standard pharmacological treatment, in addition to doctor's advice to eat more and quit smoking

(continues) 
Table 1 (continued)

\begin{tabular}{|c|c|c|c|}
\hline $\begin{array}{l}\text { Study/Country/ } \\
\text { Outcome }\end{array}$ & $\begin{array}{l}\text { Comparison/Time } \\
\text { intervention }\end{array}$ & Population & Interventions and controls/comparison conditions \\
\hline $\begin{array}{l}\text { Wijkstra et al. 49,50/ } \\
\text { Netherlands/6MWT, } \\
\text { CRO }\end{array}$ & $\begin{array}{c}\text { Home PR vs. } \\
\text { controls/3 months }\end{array}$ & $\begin{array}{l}\text { COPD patients with GOLD } \\
\text { stages III and IV } \\
\text { Intervention ( } \mathbf{n}=\mathbf{2 8} \text { ): Age: } \\
64.0 \pm 5.0 \text { years; FEV } 1 \% \\
\text { predicted): } 44.0 \pm 11.0 \\
\text { Controls ( } \mathbf{n}=15 \text { ): Age: } \\
62.0 \pm 5.0 \text { years; FEV } 1 \% \\
\text { predicted): } 45.0 \pm 9.0 \\
\text { Selection: Patients without } \\
\text { exacerbations in the } \\
\text { previous } 4 \text { weeks }\end{array}$ & $\begin{array}{l}\text { Home PR: Patients performed breathing exercises, inspiratory muscle } \\
\text { training, upper limb exercises, and exercises on a cycle ergometer (starting } \\
\text { with } 4 \text { minutes at } 60 \% \text { of maximum load reached on test and increasing } \\
\text { until } 12 \text { minutes at } 75 \% \text { maximum load obtained at baseline test). Exercises } \\
\text { lasted half an hour, twice a day, according to the individualized protocol for } \\
\text { each patient. } \\
\text { Controls: Patients received usual medication and were not instructed to } \\
\text { perform exercises }\end{array}$ \\
\hline
\end{tabular}

6MWT: Six-Minute Walk Test; COPD: chronic obstructive pulmonary disease; CRQ: Chronic Respiratory Questionnaire; FEV ${ }_{1}$ forced expiratory volume in one second; GOLD: Global Initiative for Lung Disease; ISWT: Incremental Shuttle Walk Test; MRC: Medical Research Council; OPR: outpatient pulmonary rehabilitation; PR: pulmonary rehabilitation; $\mathrm{SGRQ}$ : Saint George's Respiratory Questionnaire; $\mathrm{SpO}_{2}$ : peripheral capillary oxygen saturation; VO $\mathrm{O}_{2}$ : maximum rate of oxygen consumption; Wmax: maximum work rate.

Note: data expressed as mean \pm standard deviation.

Figure 2

Graph on risk of bias with percentages across all selected studies.

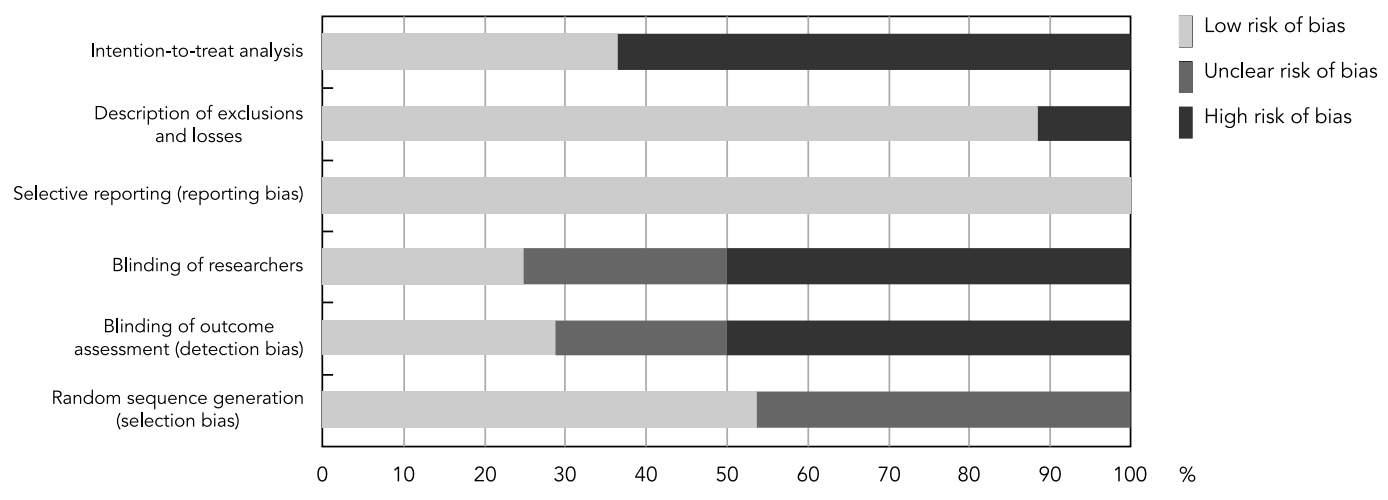

showed an effect size increase $(54.38 \mathrm{~m}, 95 \% \mathrm{CI}$ : 29.53 to $79.23, \mathrm{I}^{2}=37 \%$ ) in the studies including individuals with more severe COPD, stage III or IV according to the GOLD criteria $8\left(\mathrm{FEV}_{1}<50 \%\right.$ of predicted), while among the studies including individuals with less severe $\mathrm{COPD}\left(\mathrm{FEV}_{1}>50 \%\right.$ of predicted), no effect was found $(7.20 \mathrm{~m}, 95 \% \mathrm{CI}$ : -23.72 to $38.11, \mathrm{I}^{2}=55 \%$ ). A reduction of heterogeneity in both meta-analyses was seen (Figure 4). With regard to functional capacity measured by ISWT, significant improvement was also seen in the distance walked comparing patients who performed HCPR to controls $(78.84 \mathrm{~m}, 95 \% \mathrm{CI}$ : 43.04 to $104.64, \mathrm{I}^{2}=0 \%$ ) (Figure 5). Finally, there was a significant decrease in sensation of dyspnea assessed by MRC in HCPR compared to controls $\left(-0.21\right.$, 95\%CI: -0.42 to $\left.-0.00, \mathrm{I}^{2}=0 \%\right)$ (Figure 6).

(b) Quality of Life: Thirteen studies 17,18,19,31,33,34, $36,38,42,44,46,47,49(\mathrm{n}=521)$ assessed quality of life with CRQ and four 18,30,39,48 ( $\mathrm{n}=281)$ with SGRQ. The meta-analysis showed that participants who received the intervention showed significant improvement in the four quality of life domains as- 
Figure 3

Graph on risk of bias for each selected study.

\begin{tabular}{|c|c|c|c|c|c|c|}
\hline & 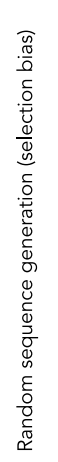 & 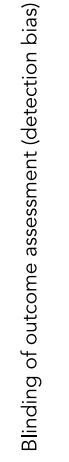 & 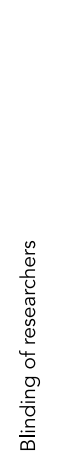 & 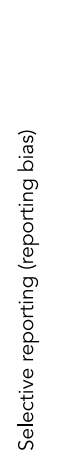 & 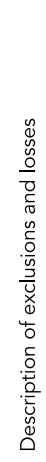 & 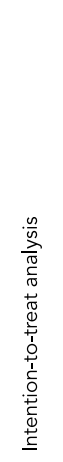 \\
\hline Akinci \& Olgun ${ }^{30}$ & $?$ & + & $?$ & + & - & \\
\hline Behnke et al. ${ }^{17}$ & $?$ & + & + & + & + & \\
\hline Cambach et al. ${ }^{31}$ & + & $?$ & $?$ & + & 4 & \\
\hline Dias et al. ${ }^{32}$ & + & 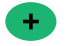 & + & + & & \\
\hline du Moulin et al. ${ }^{33}$ & + & + & + & & & \\
\hline Effing et al. ${ }^{34}$ & + & $?$ & $?$ & + & & \\
\hline Elliot et al. 35 & ? & $?$ & $?$ & + & & \\
\hline Ghanem et al. ${ }^{36}$ & $?$ & - & $(-)$ & & & \\
\hline Güell et al. ${ }^{37}$ & $?$ & + & + & & & \\
\hline Hernández et al. ${ }^{38}$ & $?$ & $(-5)$ & $(--1)$ & & & \\
\hline Ho et al. ${ }^{39}$ & 1 & & $(-$ & & & \\
\hline Jang et al. ${ }^{40}$ & ? & & 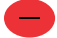 & & & \\
\hline Maltais et al. ${ }^{41}$ & + & & + & & & \\
\hline Man et al. 18 & + & & & & & \\
\hline Moore et al. ${ }^{42}$ & + & & & & & \\
\hline Murphy et al. ${ }^{43}$ & + & $?$ & $?$ & & & \\
\hline Oh et al. ${ }^{44}$ & $?$ & & & & & \\
\hline Puente-Maestu et al. 45 & + & & & & & \\
\hline Resqueti et al. ${ }^{19}$ & + & & & + & & \\
\hline Román et al. ${ }^{46}$ & \pm & ? & ? & + & & \\
\hline Singh et al. ${ }^{47}$ & ? & & & t & & \\
\hline van Wetering et al. 48 & + & + & + & + & 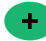 & \\
\hline Wijkstra et al. 49 & ? & - & - & + & 4 & \\
\hline Wijkstra et al. 50 & ? & & & + & + & \\
\hline
\end{tabular}


Figure 4

Meta-analysis of functional capacity in the Six-Minute Walk Test (6MWT) comparing home or community-based pulmonary rehabilitation (HCPR) to controls

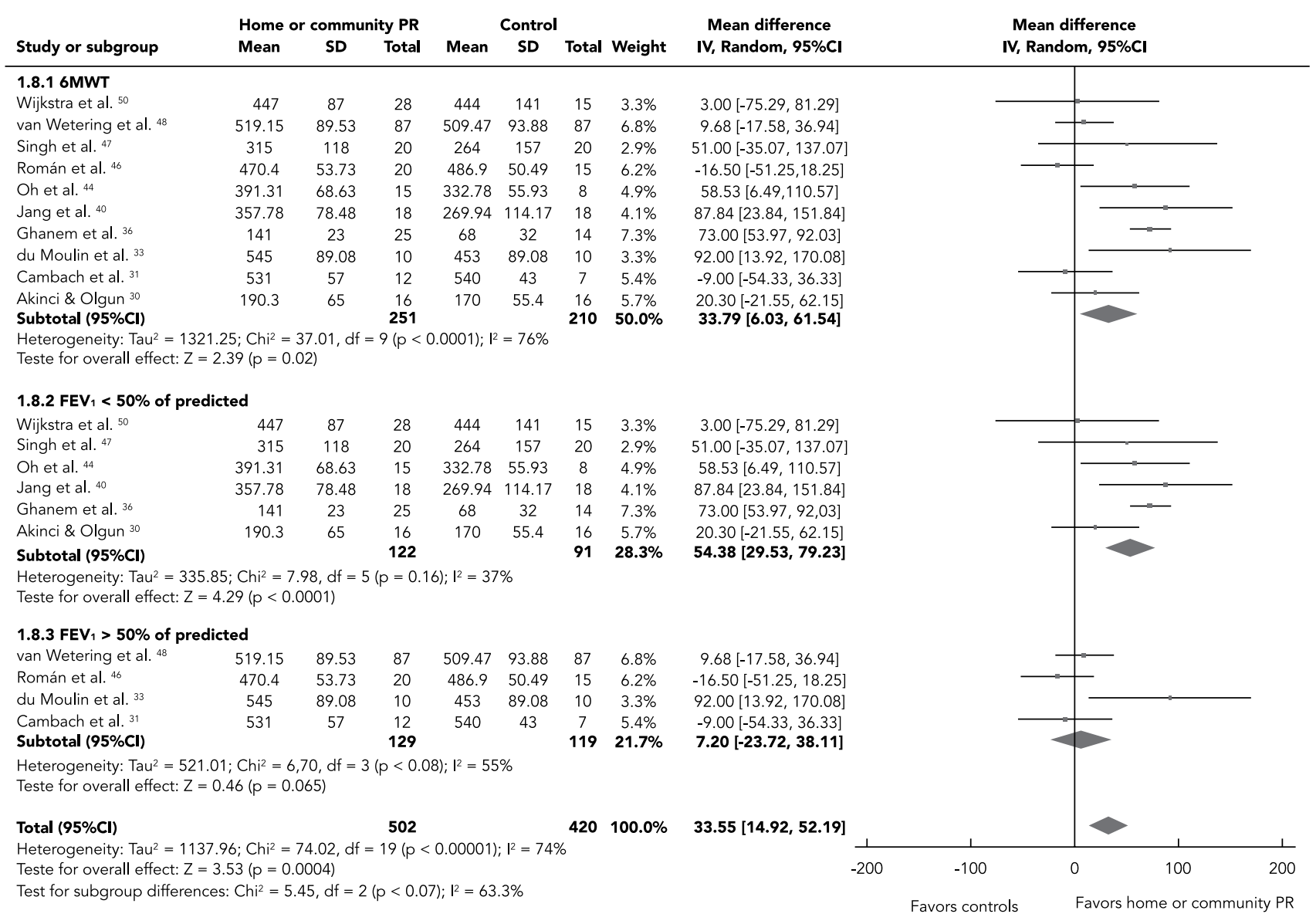

95\% Cl: 95\% confidence interval; $\mathrm{FEV}_{1}$ : forced expiratory volume in one second; PR: pulmonary rehabilitation; SD: standard deviation.

sessed by CRQ, namely Fatigue (0.79, 95\%CI: 0.51 to $\left.1.07, \mathrm{I}^{2}=49 \%\right)$, Dyspnea $(0.65,95 \% \mathrm{CI}: 0.21$ to $\left.1.09, \mathrm{I}^{2}=81 \%\right)$, Emotional Function $(0.51,95 \% \mathrm{CI}$ : 0.20 to $\left.0.83, \mathrm{I}^{2}=56 \%\right)$, and Mastery $(0.73,95 \% \mathrm{CI}$ : 0.38 to $1.08, \mathrm{I}^{2}=63 \%$ ) (Figure 7 ). Similarly, when compared to controls, patients who received HCPR also showed improvement in overall quality of life assessed by SGRQ (-9.98, 95\%CI: -17.23 to $\left.-2.74, \mathrm{I}^{2}=73 \%\right)$ and in the Activity $(-12.34$, 95\%CI: -19.54 to $\left.-5.14, \mathrm{I}^{2}=57 \%\right)$ and Psychosocial Impact (-10.70, 95\%CI: -18.89 to $-2.52, \mathrm{I}^{2}=76 \%$ ) domains, but no improvement was demonstrated in the Symptoms domain (-3.24, 95\%CI: -9.97 to $3.49, \mathrm{I}^{2}=53 \%$ ) (Figure 8 ). High heterogeneity values were explored by separating the studies into subgroups according to the characteristics of the patients' disease, risk of methodologi- cal bias in studies, countries where the studies were performed, and intervention time. None of the analyses showed a substantial decrease in heterogeneities.

\section{- Analysis 2: HCPR vs. OPR}

(a) Functional Capacity: Three studies 36,37,41 $(\mathrm{n}=334)$ assessed functional capacity using the 6MWT. When considered jointly, the interventions did not differ significantly in the distance walked in the 6MWT $(8.70 \mathrm{~m}, 95 \% \mathrm{CI}:-6.67$ to 24.08, $\mathrm{I}^{2}=0 \%$ ) (Figure 9).

(b) Quality of Life: Three studies 35,37,45 ( $\mathrm{n}=123)$ evaluated quality of life using the CRQ. The meta-analysis showed no significant difference between the interventions in the domains of Dys- 


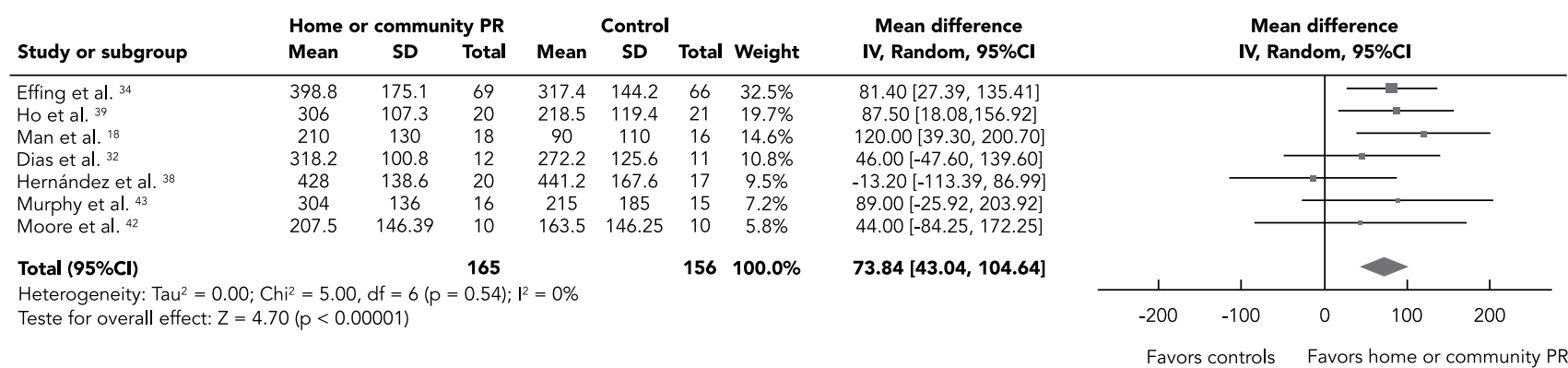

95\% Cl: 95\% confidence interval; PR: pulmonary rehabilitation; SD: standard deviation.

Figure 6

Meta-analysis of dyspnea perception in Medical Research Council (MRC) comparing home or community-based pulmonary rehabilitation (HCPR) to controls.

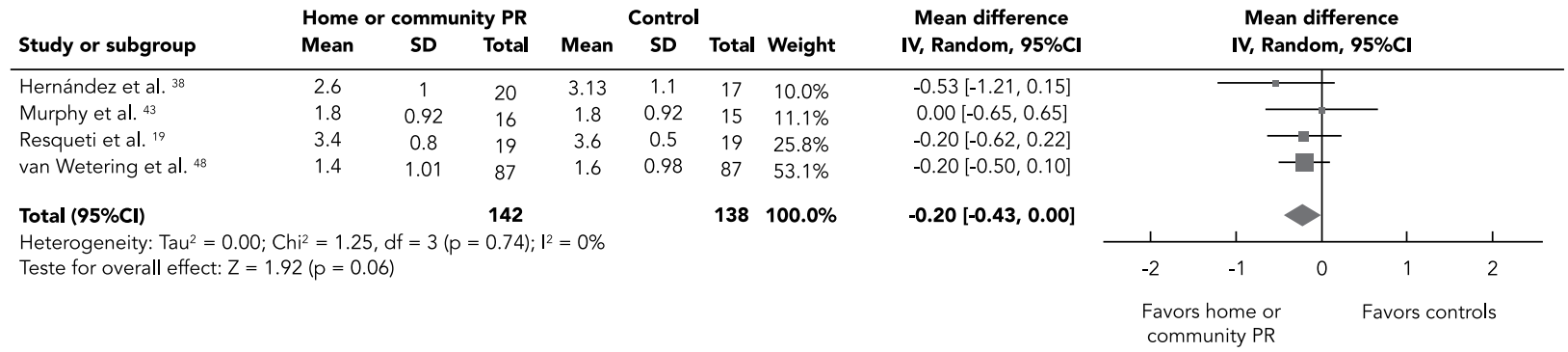

95\% Cl: 95\% confidence interval; PR: pulmonary rehabilitation; SD: standard deviation.

pnea $\left(-0.14,95 \%\right.$ CI: 0.29 to $\left.-0.57, \mathrm{I}^{2}=0 \%\right)$, Fatigue $\left(-0.18,95 \%\right.$ CI: -0.77 to $\left.0.42, \mathrm{I}^{2}=59 \%\right)$, Emotional Function (-0.23, 95\%CI: -0.99 to 0.53 , I $2=77 \%)$, or Mastery $\left(-0.14,95 \% \mathrm{CI}\right.$ : -0.95 to $\left.0.68, \mathrm{I}^{2}=69 \%\right)$ (Figure 10). Likewise, high heterogeneity values were also explored using the previously specified criteria, and no substantial decrease in heterogeneities was observed.

\section{Assessment of quality of evidence}

Assessment of the quality of evidence in this systematic review was performed for each of the outcomes evaluated by the GRADE system. The GRADE system defines well-conducted RCTs as providing high-quality evidence, even though the degree of trustworthiness and recommendation of the findings can decrease, according to a series of criteria 51. In this review, each comparison was assessed: HCPR vs. control group and HCPR vs. OPR (Supplementary Material: https:// www.dropbox.com/s/w21i0iz37pv3kuc/Mate rial\%20Suplementar\%2013.03.2016.docx?dl=0). For all the target outcomes, taking into account the considerable heterogeneity found in some analyses and/or the findings' inaccuracy, as shown by wide confidence intervals (probably due to small samples in most of the studies), the quality of the evidence was classified as moderate. Despite some studies' methodological limitations, the aspects described above were more 
Figure 7

Meta-analysis of quality of life in Chronic Respiratory Questionnaire (CRQ) comparing home or community-based pulmonary rehabilitation (HCPR) to controls.

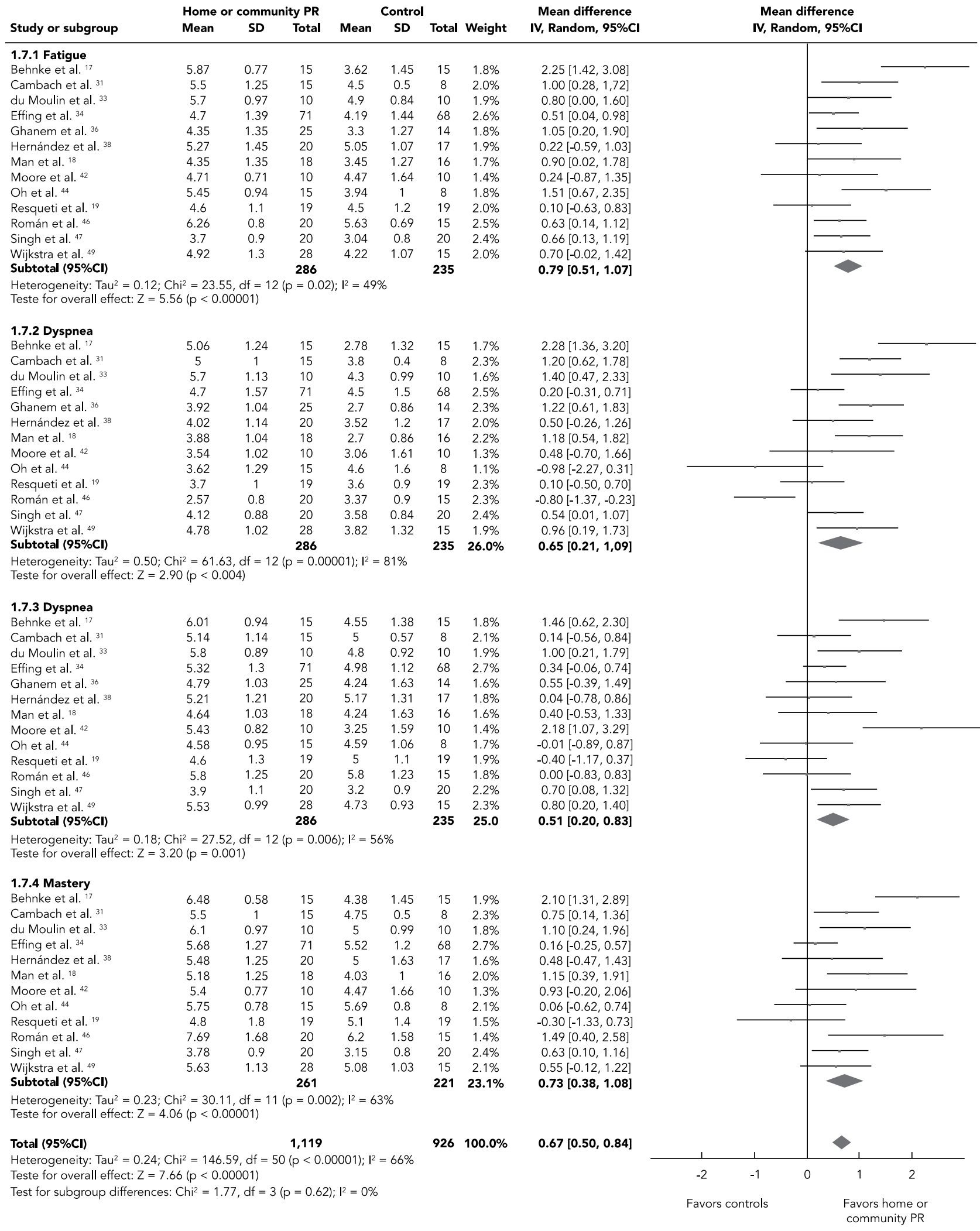

95\% Cl: 95\% confidence interval; PR: pulmonary rehabilitation; SD: standard deviation. 
Meta-analysis of quality of life in Saint George's Respiratory Questionnaire (SGRQ) comparing home or community-based pulmonary rehabilitation (HCPR) to controls.

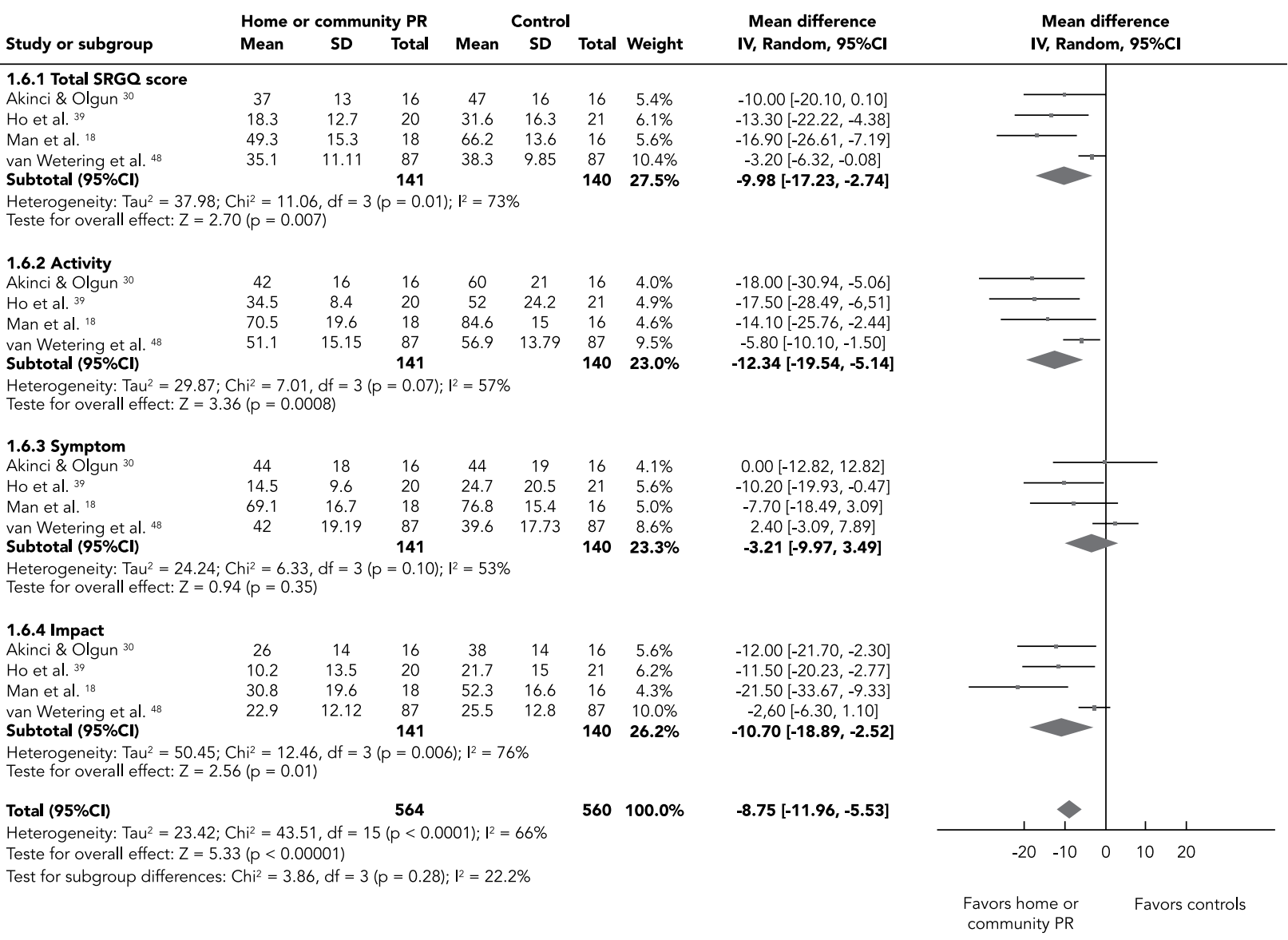

95\% Cl: 95\% confidence interval; PR: pulmonary rehabilitation; SD: standard deviation.

prevalent in assessing the quality of evidence for each outcome, since the method used to generate random sequences in many studies was not clear (which does not mean that it was inappropriate) and because double-blinding is not possible in interventions such as PR. Still, sensitivity analysis, removing studies with lower methodological quality of meta-analyses, did not significantly change the estimated effects between the outcomes or decrease the heterogeneities.

\section{Discussion}

\section{Summary of the evidence}

This systematic review and meta-analysis of RCTs assessed the influence of pulmonary rehabilitation setting, whether at home or in community groups, compared to control groups or standard outpatient pulmonary rehabilitation in patients with COPD. Target outcomes were functional capacity using the 6MWT or ISWT, dyspnea using MRC, and quality of life using SGRQ or CRQ. When compared to a control group, home or community-based PR improved functional capacity, decreased dyspnea sensation, and improved quality of life. In addition, when 
Figure 9

Meta-analysis of functional capacity in Six-Minute Walk Test (6MWT) comparing home or community-based pulmonary rehabilitation (HCPR) to outpatient pulmonary rehabilitation (OPR).

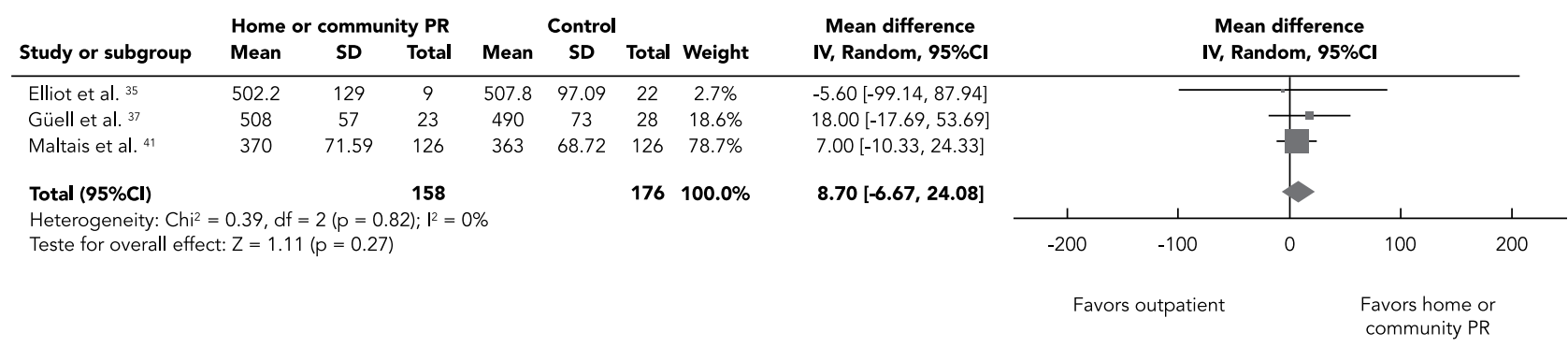

95\% Cl: 95\% confidence interval; PR: pulmonary rehabilitation; SD: standard deviation.

Figure 10

Meta-analysis of quality of life in Chronic Respiratory Questionnaire (CRQ) comparing home or community-based pulmonary rehabilitation (HCPR) to outpatient pulmonary rehabilitation (OPR).

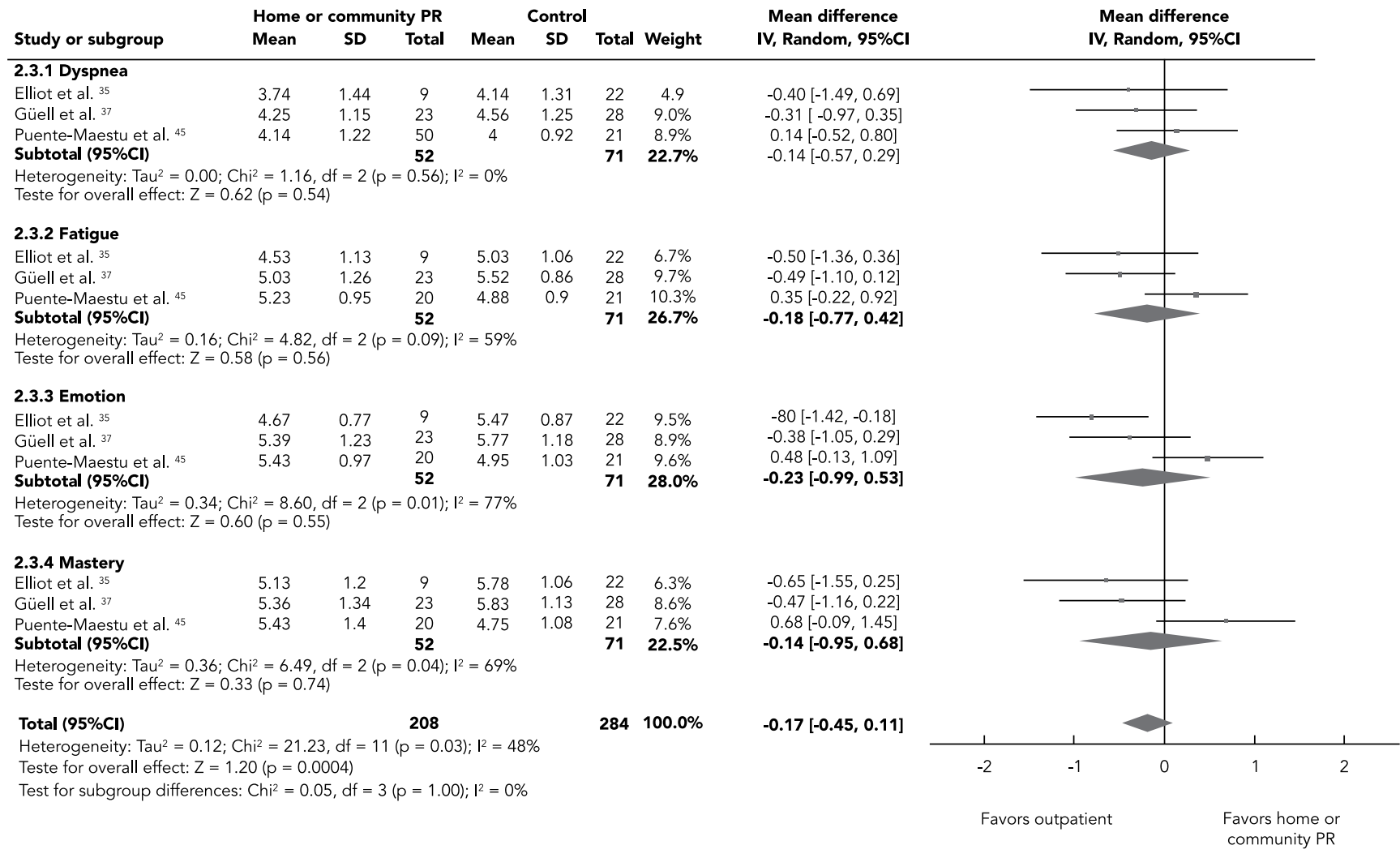

95\% Cl: 95\% confidence interval; PR: pulmonary rehabilitation; SD: standard deviation. 
compared to OPR, the effects of HCPR did not differ with regard to functional capacity or quality of life.

In the 6MWT, performance improvement in the HCPR group compared to the control group was 54.38 meters for patients with $\mathrm{FEV}_{1}<50 \%$ of predicted; an improvement of 54 meters is known to be clinically significant 49 . Moreover, studies show that the 6MWT is an excellent predictor of hospitalization and mortality among COPD patients 52,53 , i.e., the longer the distance walked in the test, the lower the odds of hospitalization and death ${ }^{52}$. The lack of effect for patients with $\mathrm{FEV}_{1}>50 \%$ of predicted may have been due to the lower functional impairment in these individuals, who would be expected to benefit less from the intervention.

Similarly, the average difference in the ISWT between the group that received HCPR and the control group was 73.85 meters, much higher than the 47.5-meter increase that is sufficient to show clinically significant improvement in this test 55 . When HCPR and OPR were compared, it was not possible to identify differences between the average distances walked in the 6MWT. Systematic reviews with meta-analysis comparing the effect of OPR to control groups found similar effect sizes as in the comparison between HCPR and controls, namely 77.7 meters (95\%CI: 12.21 to 143.20 ) 13 and 48.0 meters (95\%CI: 32.0 to 65.0 ) 56 in ISWT. These results show the strong potential of home and community programs that use fewer devices and resources to produce similar gains in functional capacity when compared to standard outpatient programs.

Both the 6MWT and ISWT show good reproducibility and good sensitivity for assessing changes in functional capacity of patients with COPD after PR programs, with 6MWT as a submaximal test and ISWT as a maximal test 57 . This demonstrates that patients undergoing HCPR can benefit in different functional aspects of physical capacity. In addition, the tests are of easy to apply and low-cost and correlate well with the maximum oxygen consumption $\left(\mathrm{VO}_{2} \max \right) 1,58$, confirming the importance of the findings in this meta-analysis.

The current study also demonstrated that HCPR, when compared to a control group, decreased the sensation of dyspnea, assessed by MRC. The index can help predict mortality risk in patients with COPD 8, and individuals with higher MRC indices have lower exercise capacity and lower quality of life 59, aspects also associated with increased risk of mortality.

Quality of life in patients receiving HCPR compared to the control group showed improvement, except in the symptoms section of the SGRQ. Considering the overall score and in other domains, the results of the selected studies showed significantly improved quality of life after completing the program. An eight-point decrease in the SGRQ score indicates a moderately effective change, while a 12-point decrease indicates highly efficient treatment 60 .

Similarly, when evaluated by CRQ, all areas showed improvement in HCPR compared to the control group. Again, comparison of HCPR and OPR showed no differences in any of the CRQ domains, demonstrating that home or communitybased programs can be as effective as outpatient pulmonary rehabilitation to improve quality of life for individuals with COPD.

These quality of life questionnaires seek to assess the degree of disability and not merely lung incapacity, since their domains tend to address the issue of disability related to psychosocial, emotional, and self-control factors and activities as well as the sensation of dyspnea and fatigue. Importantly, a 0.5-point change in CRQ may be clinically significant 14 , and in meta-analyses comparing HCPR to control groups in all domains, the mean difference exceeded 0.5 points.

Quality of life questionnaires can be better at measuring the true impact of interventions in real life, compared to the results of other tests and measures 61 . SGRQ is widely used to assess quality of life in these patients 8 . However, CRQ, also widely used 62 , has proven superior for evaluating quality of life in patients with COPD who received $P R$ 63,64.

As a whole, this study indicates that HCPR can improve functional capacity, quality of life, and sensation of dyspnea in COPD patients when compared to control interventions. This PR modality's results also resembled those of OPR, whose benefits are widely documented in the literature. Some studies have shown that HCPR is cost-effective, making it the most feasible approach for extending to larger numbers of people and improving population access 65,66 .

\section{Strengths and limitations of the review}

This systematic review proposed to answer specific research questions by rigorously following the recommendations of the Cochrane Collaboration 26 for conducting systematic reviews and meta-analyses. Among the procedures, the study protocol was published, allowing explicit reproducibility and decreasing potential selective reporting bias. A comprehensive search was conducted with no limitations on language or period, and two independent reviewers performed the study selection and data extraction. 
The various meta-analyses focused on outcomes with high clinical significance, extending the findings of systematic reviews on the topic with data up to $201223,24,25$. No relevant evidence of heterogeneities was observed in at least three of the meta-analyses, while we explored the other heterogeneities that were detected. Altogether, these characteristics gave high methodological quality to this systematic review.

In light of the findings' biological plausibility, the absence of heterogeneity in the comparisons of HCPR and control groups in ISWT and MRC and in the comparison of HCPR and OPR in 6MWT demonstrates that the results for these outcomes are reliable.

The heterogeneity in the 6MWT comparing HCPR to the control group was explored: one possible explanation for its increase is the percentage averages of predicted $\mathrm{FEV}_{1}$ in patients. Subgroup analysis showed an important decrease in heterogeneity, mainly for the group with $\mathrm{FEV}_{1}<50 \%$ of predicted. Maintenance of high heterogeneity in the analysis of studies with patients showing mean $\mathrm{FEV}_{1}>50 \%$ of predicted may have occurred due to the small number of studies included or to other differences in rehabilitation programs, since the studies included in this meta-analysis had low risk of methodological bias.

The observed heterogeneity in quality of life outcomes is somewhat expected, since quality of life concepts can change according to various study contexts and cultural characteristics, despite the validation of questionnaires for each country. In addition, such analyses always show heterogeneity between studies on the basis of their clinical and methodological diversity, even though the tests are unable to detect it; the effect's magnitude and direction should always be considered, regardless of the strength of evidence in assessing the estimates 26 .

Although this review showed substantial heterogeneity in some analyses with regard to quality of life, HCPR clearly benefits COPD patients, based on the direction and size of effects. Subgroup analyses sought to explain this heterogeneity by considering differences in intervention times, methodological quality, and degree of patients' commitment. However, none of the analyses revealed differences among subgroups in effect size or direction, making it impossible to explain the differences that were found. We thus assume that the heterogeneity is due to the large number of studies involved in some analyses, the variety of types of intervention, and the sociocultural diversity of subjects.

Various factors limited the quality of evidence identified in this systematic review and the de- gree of confidence in some of the recommendations. The main limiting factor is the lack of reports of prior calculation of sample size and statistical power in the selected studies, some of which included small numbers of patients, thereby increasing the uncertainty in the estimates generated by the meta-analyses and the potential publication bias, although none of the selected studies had received industry funding. Additionally, most studies identified a limited post-intervention assessment period, thus preventing assessment of the long-term efficacy of HCPR and its impact on morbidity and mortality.

The review also detected low methodological quality in many studies that did not address or provide details on essential procedures for reducing the risk of bias in RCTs: adequacy of the random sequence generation, blinding of study teams and reviewers, intention-to-treat analysis, and the impact of loss to follow-up between groups. RCTs on HCPR are thus needed with larger samples, extended follow-up, and greater methodological rigor in order to increase the confidence in their degree of recommendation, given the diversity of clinical scenarios and patient care in COPD.

The summary of these issues involving methodological quality, heterogeneity, and imprecision is taken into account when assessing a study's quality. For all target outcomes in both comparisons, the quality of evidence was considered moderate. That is, the results should be interpreted with caution. Studies with greater statistical power and more appropriate and uniform methodologies can lead to small changes in effect size for the target outcomes. Nonetheless, the results are highly valid, considering the direction of the effects, the significance of the statistical tests, and their clinical relevance.

\section{Differences between this and other reviews}

This was not the first systematic review of studies on COPD and PR, although it was the first to directly compare HCPR and OPR. While this study was in progress, a systematic review was published with a meta-analysis of 18 studies comparing HCPR and control groups, published up to 2012 23. The authors identified only 814 studies in databases, without using a sensitive search for RCTs and including studies that did not meet our inclusion criteria (since they did not involve exercises, were not RCTs, or did not meet our criteria for the minimum intervention time). The three meta-analyses involved three studies on the outcome of the SGRQ, two using the Borg scale, and eight the 6MWT. The authors' results were similar to ours, indicating that HCPR, compared 
to control groups, improves functional capacity, relieves the sensation of dyspnea, and improves quality of life in COPD.

Another systematic review without a metaanalysis 25 compared home-based PR with control groups or non-home-based PR and identified 888 studies, of which 12 were included. Most of these studies found that programs involving aerobic endurance training improve quality of life and exercise capacity for patients with COPD. In agreement with our findings, the authors concluded that unsupervised home-based PR is useful and, if properly done, can be an equivalent alternative to OPR programs.

Another systematic review 24 evaluated the impact of home-based physical therapy on activities of daily living in COPD patients. Of the 1,686 studies identified by the review, seven were included and three were included in a meta-analysis. The authors concluded that home exercise and training of inspiratory muscles decreases the sensation of dyspnea, findings corroborated by the current systematic review's meta-analysis.

\section{Implications for practice}

HCPR meets the recommendations of various public health programs around the world, seeking to decentralize and distribute specialized health services, drawing them closer to the population. HCPR thus potentially applies to countries with universal access in their health care systems.
This systematic review's findings thus corroborate data from other studies, besides increasing the power of evidence on this issue.

HCPR can improve functional capacity, reduce dyspnea, and improve quality of life in patients with COPD, and these benefits are comparable to those of OPR in relation to functional capacity and quality of life. However, concerning the positive effects of this intervention, feasibility studies are still needed to implement these programs, including their suitability in relation to different clinical needs and local contexts. Some alternatives, such as telephone reminders or health worker visits in conjunction with HCPR, could be adopted to increase treatment adherence and monitor patients' symptoms and their adaptation to physical training.

Some issues should be addressed in greater depth in future studies, such as cost-effectiveness of HCPR, considering basic requirements for modeling PR programs, like staff, time, and patient monitoring, among others. Studies should also compare the actual costs of HCPR and OPR, including health services and costs to individuals, besides comparing adherence, number of subsequent hospitalizations, and survival analysis. This is crucial information for clinical decision-making and planning health policies and services, which can be more specific to each population's reality, available human and financial resources, and the respective cultural context.

\section{Contributors}

L. F. Neves was the first reviewer and contributed to the planning, project design, database search, data extraction, analyses, writing of the manuscript, and revisions. M. H. Reis was the second reviewer and contributed to the planning, project design, database search, data extraction, and revisions. T. R. Gonçalves was the third reviewer and contributed to the planning, project design, database search, data extraction, analyses, writing of the manuscript, and revisions.

\section{Note}

The complete search strategy for this systematic review, the funnel plot for the only outcome eligible for this analysis, and the table with the summary of findings (GRADE) are available at https://www.dropbox.com/s/ w21i0iz37pv3kuc/Material\%20Suplementar\%20 13.03.2016.docx? $\mathrm{dl}=0$. 


\section{References}

1. Sociedade Brasileira de Pneumologia e Tisiologia. II consenso brasileiro sobre doença pulmonar obstrutiva crônica - DPOC. J Bras Pneumol 2004; 30 Suppl 5:S1-S42.

2. Celli BR, MacNee W. Standards for the diagnosis and treatment of patients with COPD: a summary of the ATS/ERS position paper. Eur Respir J 2004; 23:932-46.

3. Sin DD, Anthonisen NR, Soriano JB, Agusti AG. Mortality in COPD: role of comorbidities. Eur Respir J 2006; 28:1245-57.

4. Jones PW, Brusselle G, Dal Negro RW, Ferrer M, Kardos P, Levy ML, et al. Properties of the COPD assessment test in a cross-sectional European study. Eur Respir J 2011; 38:29-35.

5. Perera PN, Armstrong EP, Sherrill DL, Skrepnek GH. Acute exacerbations of COPD in the United States: inpatient burden and predictors of costs and mortality. COPD 2012; 9:131-41.

6. Antunes FP, Costa MC, Paim JS, Vieira-da-Silva LM, Santos CA, Cruz AA, et al. Trends in hospitalizations for respiratory diseases in Salvador, Bahia State, Brazil, 1998-2009. Cad Saúde Pública 2012; 28:869-77.

7. Hoogendoorn M, Hoogenveen RT, Rutten-van Molken MP, Vestbo J, Feenstra TL. Case fatality of COPD exacerbations: a meta-analysis and statistical modelling approach. Eur Respir J 2011; 37: 508-15.

8. Vestbo J, Hurd SS, Agusti AG, Jones PW, Vogelmeier C, Anzueto A, et al. Global strategy for the diagnosis, management and prevention of chronic obstructive pulmonary disease, GOLD Executive Summary. Am J Respir Crit Care Med 2013; 187:347-65.

9. Spruit MA, Singh SJ, Garvey C, ZuWallack R, Nici L, Rochester C, et al. An official American Thoracic Society/European Respiratory Society statement: key concepts and advances in pulmonary rehabilitation. Am J Respir Crit Care Med 2013; 188:e13-64.

10. Ries AL, Bauldoff GS, Carlin BW, Casaburi R, Emery CF, Mahler DA, et al. Pulmonary rehabilitation: joint ACCP/AACVPR evidence-based clinical practice guidelines. Chest 2007; 131(5 Suppl):4S-42S.

11. Sociedade Brasileira de Cardiologia. Diretriz de reabilitação cardiopulmonar e metabólica: aspectos práticos e responsabilidades. Arq Bras Cardiol 2006; 86:74-82.

12. Nici L, Donner C, Wouters E, Zuwallack R, Ambrosino N, Bourbeau J, et al. American Thoracic Society/European Respiratory Society statement on pulmonary rehabilitation. Am J Respir Crit Care Med 2006; 173:1390-413.

13. Puhan MA, Gimeno-Santos E, Scharplatz M, Troosters T, Walters EH, Steurer J. Pulmonary rehabilitation following exacerbations of chronic obstructive pulmonary disease. Cochrane Database Syst Rev 2011; (1):CD005305.

14. Lacasse Y, Wong E, Guyatt GH, King D, Cook DJ, Goldstein RS. Meta-analysis of respiratory rehabilitation in chronic obstructive pulmonary disease. Lancet 1996; 348:1115-9.
15. Wehrmeister FC, Knorst M, Jardim JR, Macedo EC, Noal RB, Martinez-Mesa J, et al. Pulmonary rehabilitation programs for patients with COPD. J Bras Pneumol 2011; 37:544-55.

16. Neves LF, Reis MH, Plentz RD, Matte DL, Coronel CC, Sbruzzi G. Expiratory and expiratory plus inspiratory muscle training improves respiratory muscle strength in subjects with COPD: systematic review. Respir Care 2014; 59:1381-8.

17. Behnke M, Taube C, Kirsten D, Lehnigk B, Jörres RA, Magnussen H. Home-based exercise is capable of preserving hospital-based improvements in severe chronic obstructive pulmonary disease. Respir Med 2000; 94(12). http://onlinelibrary.wi ley.com/o/cochrane/clcentral/articles/094/CN00330094/frame.html.

18. Man WD, Polkey MI, Donaldson N, Gray BJ, Moxham J. Community pulmonary rehabilitation after hospitalisation for acute exacerbations of chronic obstructive pulmonary disease: randomised controlled study. BMJ 2004; 329:1209.

19. Resqueti VR, Gorostiza A, Galdiz JB, Lopez de Santa Maria E, Casan Clara P, Guell Rous R. Benefits of a home-based pulmonary rehabilitation program for patients with severe chronic obstructive pulmonary disease. Arch Bronconeumol 2007; 43: 599-604.

20. Strijbos JH, Postma DS, van Altena R, Gimeno F, Koeter GH. A comparison between an outpatient hospital-based pulmonary rehabilitation program and a home-care pulmonary rehabilitation program in patients with COPD. A follow-up of 18 months. Chest 1996; 109:366-72.

21. Guell MR, de Lucas P, Galdiz JB, Montemayor T, Rodriguez Gonzalez-Moro JM, Gorostiza A, et al. Home vs hospital-based pulmonary rehabilitation for patients with chronic obstructive pulmonary disease: a Spanish multicenter trial. Arch Bronconeumol 2008; 44:512-8.

22. Mendes de Oliveira JC, Studart Leitao Filho FS, Malosa Sampaio LM, Negrinho de Oliveira AC, Hirata $\mathrm{RP}$, Costa $\mathrm{D}$, et al. Outpatient vs. home-based pulmonary rehabilitation in COPD: a randomized controlled trial. Multidiscip Respir Med 2010; 5:401-8.

23. Liu XL, Tan JY, Wang T, Zhang Q, Zhang M, Yao LQ, et al. Effectiveness of home-based pulmonary rehabilitation for patients with chronic obstructive pulmonary disease: a meta-analysis of randomized controlled trials. Rehabil Nurs 2014; 39: 36-59.

24. Thomas MJ, Simpson J, Riley R, Grant E. The impact of home-based physiotherapy interventions on breathlessness during activities of daily living in severe COPD: a systematic review. Physiotherapy 2010; 96:108-19.

25. Vieira DS, Maltais F, Bourbeau J. Home-based pulmonary rehabilitation in chronic obstructive pulmonary disease patients. Curr Opin Pulm Med 2010; 16:134-43.

26. Higgins J, Green S, editors. Cochrane handbook for systematic reviews of interventions. Chichester: Wiley; 2008. 
27. Moher D, Liberati A, Tetzlaff J, Altman DG. Reprint-preferred reporting items for systematic reviews and meta-analyses: the PRISMA statement. Phys Ther 2009; 89:873-80.

28. Neves LF, Reis MH, Gonçalves TR. Home or community based pulmonary rehabilitation for patients with chronic obstructive pulmonary disease: systematic review and meta-analysis of randomized clinical trials. http://www. crd.york.ac.uk/PROSPERO/display_record. asp?ID=CRD42014007295 (accessed on 05/ May/2016).

29. Neves LF. Reabilitação pulmonar domiciliar ou comunitária para portadores de doença pulmonar obstrutiva crônica: revisão sistemática e meta-análise de ensaios clínicos randomizados [Dissertação de Mestrado]. São Leopoldo: Programa de Pós-graduação em Saúde Coletiva, Universidade do Vale do Rio dos Sinos; 2014.

30. Akinci AC, Olgun N. The effectiveness of nurseled, home-based pulmonary rehabilitation in patients with COPD in Turkey. Rehabil Nurs 2011; 36 : 159-65.

31. Cambach W, Chadwick-Straver RV, Wagenaar RC, Keimpema AR, Kemper HC. The effects of a community-based pulmonary rehabilitation programme on exercise tolerance and quality of life: a randomized controlled trial. Eur Respir J 1997; 10:104-13.

32. Dias FD, Sampaio LMM, da Silva GA, Dantas Gomes ÉLF, do Nascimento ESP, Alves VLS, et al. Home-based pulmonary rehabilitation in patients with chronic obstructive pulmonary disease: a randomized clinical trial. Int J Chron Obstruct Pulmon Dis 2013; 8:537-44.

33. du Moulin M, Taube K, Wegscheider K, Behnke $\mathrm{M}$, Bussche H. Home-based exercise training as maintenance after outpatient pulmonary rehabilitation. Respiration 2009; 77:139-45.

34. Effing T, Zielhuis G, Kerstjens $\mathrm{H}$, van der Valk P, van der Palen J. Community based physiotherapeutic exercise in COPD self-management: a randomised controlled trial. Respir Med 2011; 105:418-26.

35. Elliott M, Watson C, Wilkinson E, Musk AW, Lake FR. Short- and long-term hospital and community exercise programmes for patients with chronic obstructive pulmonary disease. Respirology 2004; 9:345-51.

36. Ghanem M, Elaal EA, Mehany M, Tolba K. Homebased pulmonary rehabilitation program: effect on exercise tolerance and quality of life in chronic obstructive pulmonary disease patients. Ann Thorac Med 2010; 5:18-25.

37. Güell MR, De Lucas P, Gáldiz JB, Montemayor T, González-Moro JMR, Gorostiza A, et al. Home vs hospital-based pulmonary rehabilitation for patients with chronic obstructive pulmonary disease: a Spanish multicenter trial. Arch Bronconeumol 2008; 44:512-8.

38. Hernández MTE, Rubio TM, Ruiz FO, Riera HS, Gil RS, Gómez JC. Results of a home-based training program for patients with COPD. Chest 2000; 118:106-14.
39. Ho CF, Maa SH, Shyu YIL, Lai YT, Hung TC, Chen HC. Effectiveness of paced walking to music at home for patients with COPD. COPD 2012; 9: 447-57.

40. Jang HJ, Jung YK. The effects of self-efficacy promoting pulmonary rehabilitation program in outpatients with chronic obstructive pulmonary disease. Tuberc Respir Dis (Seoul) 2006; 61:533-46.

41. Maltais F, Bourbeau J, Shapiro S, Lacasse Y, Perrault $\mathrm{H}$, Baltzan $\mathrm{M}$, et al. Effects of home-based pulmonary rehabilitation in patients with chronic obstructive pulmonary disease: a randomized trial. Ann Intern Med 2008; 149:869-78.

42. Moore J, Fiddler H, Seymour J, Grant A, Jolley C, Johnson L, et al. Effect of a home exercise video programme in patients with chronic obstructive pulmonary disease. J Rehabil Med 2009; 41: 195-200.

43. Murphy N, Bell C, Costello RW. Extending a home from hospital care programme for COPD exacerbations to include pulmonary rehabilitation. Respir Med 2005; 99:1297-302.

44. Oh EG. The effects of home-based pulmonary rehabilitation in patients with chronic lung disease. Int J Nurs Stud 2003; 40:873-9.

45. Puente-Maestu L, Sánz ML, Sánz P, Cubillo JM, Mayol J, Casaburi R. Comparison of effects of supervised versus self-monitored training programmes in patients with chronic obstructive pulmonary disease. Eur Respir J 2000; 15:517-25.

46. Román M, Larraz C, Gómez A, Ripoll J, Mir I, Miranda EZ, et al. Efficacy of pulmonary rehabilitation in patients with moderate chronic obstructive pulmonary disease: a randomized controlled trial. BMC Fam Pract 2013; 14:21.

47. Singh V, Khandelwal DC, Khandelwal R, Abusaria S. Pulmonary rehabilitation in patients with chronic obstructive pulmonary disease. Indian J Chest Dis Allied Sci 2003; 45:13-7.

48. van Wetering CR, Hoogendoorn M, Mol SJM, Rutten-van Mölken MPMH, Schols AM. Short- and long-term efficacy of a community-based COPD management programme in less advanced COPD: a randomised controlled trial. Thorax 2010; 65: 7-13.

49. Wijkstra PJ, van Altena R, Kraan J, Otten V, Postma DS, Koeter GH. Quality of life in patients with chronic obstructive pulmonary disease improves after rehabilitation at home. Eur Respir J 1994; 7:269-73.

50. Wijkstra PJ, Van Mark TWD, Kraan J, van Altena R, Koëter GH, Postma DS. Long-term effects of home rehabilitation on physical performance in chronic obstructive pulmonary disease. Am J Respir Crit Care Med 1996; 153:1234-41.

51. Guyatt G, Oxman AD, Akl EA, Kunz R, Vist G, Brozek J, et al. GRADE guidelines: 1. IntroductionGRADE evidence profiles and summary of findings tables. J Clin Epidemiol 2011; 64:383-94.

52. Kessler R, Faller M, Fourgaut G, Mennecier B, Weitzenblum E. Predictive factors of hospitalization for acute exacerbation in a series of 64 patients with chronic obstructive pulmonary disease. Am J Respir Crit Care Med 1999; 159:158-64. 
53. Pinto-Plata VM, Cote C, Cabral H, Taylor J, Celli BR. The 6-min walk distance: change over time and value as a predictor of survival in severe COPD. Eur Respir J 2004; 23:28-33.

54. Redelmeier DA, Bayoumi AM, Goldstein RS, Guyatt $\mathrm{GH}$. Interpreting small differences in functional status: the Six Minute Walk test in chronic lung disease patients. Am J Respir Crit Care Med 1997; 155:1278-82.

55. Singh SJ, Jones PW, Evans R, Morgan MD. Minimum clinically important improvement for the incremental shuttle walking test. Thorax 2008; 63:775-7.

56. Lacasse Y, Martin S, Lasserson TJ, Goldstein RS. Meta-analysis of respiratory rehabilitation in chronic obstructive pulmonary disease. A Cochrane systematic review. Eura Medicophys 2007; 43:475-85.

57. Vilaro J, Resqueti V, Fregonezi G. Clinical assessment of exercise capacity in patients with chronic obstructive pulmonary disease. Rev Bras Fisioter 2008; 12:249-59.

58. Cote CG, Pinto-Plata V, Kasprzyk K, Dordelly LJ, Celli BR. The 6-min walk distance, peak oxygen uptake, and mortality in COPD. Chest 2007; 132:1778-85.

59. Bestall J, Paul E, Garrod R, Garnham R, Jones P, Wedzicha J. Usefulness of the Medical Research Council (MRC) dyspnoea scale as a measure of disability in patients with chronic obstructive pulmonary disease. Thorax 1999; 54:581-6.
60. Jones PW. Interpreting thresholds for a clinically significant change in health status in asthma and COPD. Eur Respir J 2002; 19:398-404.

61. Camp PG, Appleton J, Reid WD. Quality of life after pulmonary rehabilitation: assessing change using quantitative and qualitative methods. Phys Ther 2000; 80:986-95.

62. Moreira GL, Pitta F, Ramos D, Nascimento CS, Barzon D, Kovelis D, et al. Portuguese-language version of the Chronic Respiratory Questionnaire: a validity and reproducibility study. J Bras Pneumol 2009; 35:737-44.

63. Puhan MA, Guyatt GH, Goldstein R, Mador J, McKim D, Stahl E, et al. Relative responsiveness of the Chronic Respiratory Questionnaire, St. Georges Respiratory Questionnaire and four other healthrelated quality of life instruments for patients with chronic lung disease. Respir Med 2007; 101:308-16.

64. Singh SJ, Sodergren SC, Hyland ME, Williams J, Morgan MD. A comparison of three disease-specific and two generic health-status measures to evaluate the outcome of pulmonary rehabilitation in COPD. Respir Med 2001; 95:71-7.

65. Golmohammadi K, Jacobs P, Sin DD. Economic evaluation of a community-based pulmonary rehabilitation program for chronic obstructive pulmonary disease. Lung 2004; 182:187-96.

66. Hoogendoorn M, van Wetering CR, Schols AM, Rutten-van Molken MP. Is Interdisciplinary Community-based COPD Management (INTERCOM) cost-effective? Eur Respir J 2010; 35:79-87. 


\section{Resumo}

A doença pulmonar obstrutiva crônica (DPOC) é uma das principais causas de morte e morbidade em todo o mundo e a reabilitação pulmonar ambulatorial (RPA) demonstra benefícios positivos. O objetivo deste estudo foi investigar os efeitos da reabilitação pulmonar domiciliar ou comunitária (RPDC) em indivíduos com DPOC. Esta revisão sistemática e meta-análise de ensaios clínicos randomizados comparou os efeitos de $R P D C$ vs. controle e RPDC vs. RPA na capacidade funcional, dispneia e qualidade de vida de indivíduos com DPOC. Foram identificadas 3.172 citações em bancos de dados e 23 foram incluídas nesta revisão. A RPDC foi superior ao grupo controle para a capacidade funcional no Teste da Caminhada de Seis Minutos e no Teste de Caminhada com Carga Progressiva, para dispneia e para qualidade de vida no Saint George's Respiratory Questionnaire $e$ no Chronic Respiratory Questionnaire. Quando RPDC e RPA foram comparados, não houve diferença entre os efeitos de intervenções nem na capacidade funcional nem na qualidade de vida. A melhora foi maior nos pacientes com mais obtrução brônquica medida pelo VEF. . RPDC melhora capacidade funcional e qualidade de vida, diminui a sensação de dispneia e de seus benefícios em capacidade funcional e qualidade de vida podem ser comparados aos obtidos em RPA para indivíduos com DPOC.

Reabilitação; Tecnologia Biomédica; Doença Pulmonar Obstrutiva Crônica

\section{Resumen}

La enfermedad pulmonar obstructiva crónica (EPOC) es una de las principales causas de muerte y morbilidad en todo el mundo, contando la rehabilitación pulmonar ambulatoria (RPA) con beneficios positivos. El objetivo de este estudio fue investigar los efectos de la rehabilitación pulmonar domiciliaria o comunitaria (RPDC) en individuos con EPOC. Esta revisión sistemática y el metaanálisis de ensayos clínicos randomizados comparó los efectos de RPDC vs. control y RPDC vs. RPA en la capacidad funcional, disnea y calidad de vida de individuos con EPOC. Se identificaron 3.172 citas en bancos de datos y 23 se incluyeron en esta revisión. La RPDC fue superior al grupo control, respecto a la capacidad funcional en el Test de Paseo de 6 Minutos y en el Prueba de Caminata de Carga Progresiva; para la disnea y calidad de vida en el Saint George's Respiratory Questionnaire y en el Chronic Respiratory Questionnaire. Cuando se compararon RPDC y RPA, no hubo diferencia entre los efectos de intervenciones, ni en la capacidad funcional, ni en la calidad de vida. La mejora fue mayor en los pacientes con más obstrucción bronquial, medida por el volumen espiratorio forzado durante el primer segundo. La RPDC mejora la capacidad funcional y calidad de vida, disminuye la sensación de disnea y sus beneficios en capacidad funcional y calidad de vida pueden ser comparados a los obtenidos en RPA para individuos con EPOC.

Rehabilitación; Tecnología Biomédica; Enfermedad Pulmonar Obstructiva Crónica
Submitted on $01 /$ Jun/2015

Final version resubmitted on 17/Mar/2016

Approved on 28/Mar/2016 